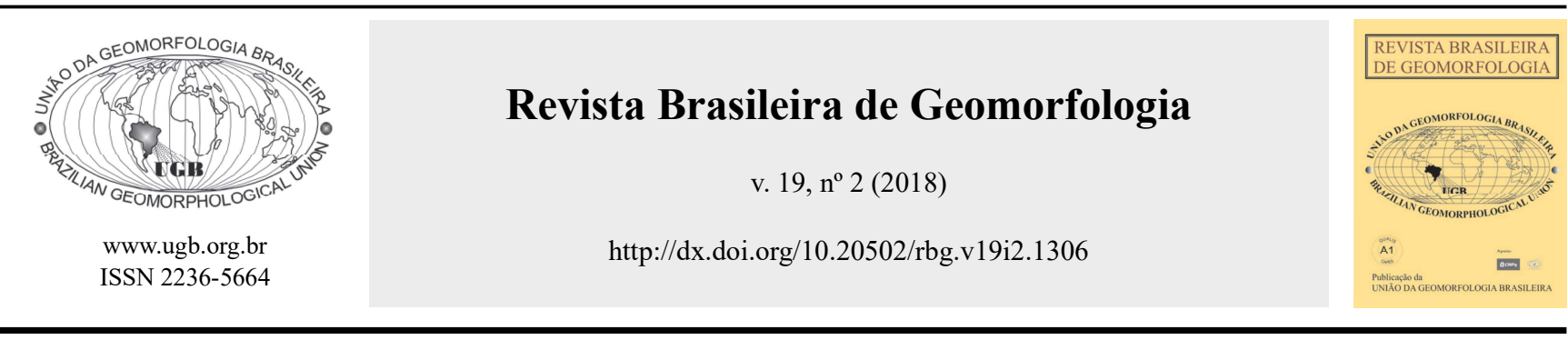

\title{
RELAÇÕES ENTRE PERDAS GEOQUÍMICAS E CONFIGURAÇÃO GEOMORFOLÓGICA DE BACIAS FLUVIAIS DE BAIXA ORDEM NA BORDA OESTE DO ESPINHAÇO MERIDIONAL (MINAS GERAIS)
}

\section{RELATIONSHIP BETWEEN CHEMICAL LOSSES AND GEOMORPHOLOGICAL SETTING OF LOW-ORDER HYDROGRAPHIC CATCHMENTS IN THE WESTERN EDGE OF SERRA DO ESPINHAÇO RIDGE (MINAS GERAIS)}

\author{
Antônio Pereira Magalhães Júnior \\ Departamento de Geografia, Universidade Federal de Minas Gerais \\ Av. Antônio Carlos, 6627, Belo Horizonte, Minas Gerais. CEP: 31270-901. Brasil
}

Email: antonio.magalhaes.ufmg@gmail.com

Luísa Lima Borges Ferreira

Departamento de Geografia, Universidade Federal de Minas Gerais Av. Antônio Carlos, 6627, Belo Horizonte, Minas Gerais. CEP: 31270-901. Brasil

Email: luisalbferreira06@gmail.com

Miguel Fernandes Felippe

Departamento de Geociências, Universidade Federal de Juiz de Fora Rua José Lourenço Kelmer, s/n, Juiz de Fora, Minas Gerais. CEP: 36036-900. Brasil Email:miguel.felippe@ufjf.edu.br

Fernando César da Costa

Departamento de Geografia, Universidade Federal de Minas Gerais Av. Antônio Carlos, 6627, Belo Horizonte, Minas Gerais. CEP: 31270-901. Brasil

Email:labgeomorfo@igc.ufmg.br

Adolf Heinrich Horn

Departamento de Geologia, Universidade Federal de Minas Gerais Av. Antônio Carlos, 6627, Belo Horizonte, Minas Gerais. CEP: 31270-901. Brasil

Email:hahorn@gmail.com

\section{Informações sobre o Artigo}

Recebido (Received): 10/09/2017

Aceito (Accepted): $10 / 01 / 2018$

Palavras-chave:

Dinâmica Hidrogeoquímica; Nascentes; Geomorfologia Fluvial.

\section{Resumo:}

Este artigo traz resultados da relação entre perdas geoquímicas e a configuração geomorfológica de bacias fluviais de baixa ordem ( $2^{\mathrm{a}}$ ordem segundo a classificação de Strahler, 1952) na borda oeste da serra do Espinhaço Meridional, a partir dos estudos de caso de duas bacias hidrográficas. Foram coletadas amostras de água de nascentes e cursos fluviais de $1^{\mathrm{a}}$ e $2^{\mathrm{a}}$ ordens em campanhas de campo trimestrais entre novembro de 2015 e junho de 2017. Em laboratório, foram analisados os parâmetros TDS (Sólidos Totais Dissolvidos), sílica, alcalinidade e 
Keywords:

Hidrogeochemical Dynamics; Springs; Fluvial Geomorphology.

condutividade elétrica. Os resultados mostram a dinâmica geoquímica das águas da Serra do Cipó controlada por quartzitos. As baixas taxas de concentração dos parâmetros analisados expressam a resistência litológica à erosão geoquímica. Registra-se aumento de perdas geoquímicas ao longo das redes de drenagem, fato intensificado, em vários casos, pela existência de nascentes difusas e áreas úmidas que favorecem a relativa estagnação das águas superficiais em coberturas pedológicas orgânicas. O maior enriquecimento geoquímico pode derivar dos substratos geológicos ou das coberturas orgânicas em função do regime pluviométrico.

\begin{abstract}
:
This paper presents the results of the relationship between geochemical losses and geomorphological setting of low-order hydrographic catchments (2nd order according to Strahler's classification, 1952) on the western edge of the Serra do Espinhaço Ridge, based on two case studies. Water samples were collected from springs and water channels (first and second orders) in quarterly field campaigns between November 2015 and June 2017. The following parameters were analyzed in laboratory: TDS (Total Dissolved Solids), silica, alkalinity and electrical conductivity. The results show the geochemical dynamics of Serra do Cipó waters, controlled by quartzites. The low concentration rates of the analyzed parameters demonstrate the lithological resistance to geochemical erosion. There is an increase in geochemical losses along the drainage networks, a fact intensified in many cases by diffuse springs and wetlands that favor the relative stagnation of superficial water in organic soil coverings. The greatest geochemical enrichment could be derived from geological substrates or from organic coverings in accordance with the rainfall regime.
\end{abstract}

\section{Introdução}

O papel das nascentes e de cursos d'água de ordem hierárquica inferior $\left(1^{\mathrm{a}} \mathrm{e} 2^{\mathrm{a}}\right.$ ordens $)$ na perda de massa continental é ainda pouco estudado e conhecido na literatura, em parte devido a expressarem a parcela subterrânea (não visível) da atuação dos processos de desnudação. No Brasil, os estudos também se concentram nas perdas geoquímicas derivadas de fluxos superficiais (SALGADO; VALADÃO, 2003; SALGADO et al., 2004; SARDINHA et al., 2012). As pesquisas sobre o tema envolvendo nascentes são ainda pouco frequentes (MAGALHÃES JR; FELIPPE, 2012; FELIPPE, 2013).

Este trabalho visa contribuir para as discussões sobre o significado das nascentes e canais de ordens inferiores nas perdas geoquímicas e na evolução do relevo, especificamente na borda oeste da Serra do Espinhaço, estado de Minas Gerais. Este significado passa pelas implicações da configuração geomorfológica destes sistemas fluviais, já que as características superficiais de escala local podem ter uma influência decisiva no enriquecimento geoquímico das águas.

A Serra do Espinhaço é um dos mais extensos domínios geológicos e geomorfológicos do país, estendendo-se da borda norte do Quadrilátero Ferrífero, a sul, até o norte do estado da Bahia. É, deste modo, um imponente divisor hidrográfico entre as bacias dos rios São Francisco, Doce e Jequitinhonha, cuja dinâmica geoquímica espaço-temporal ainda foi pouco estudada. O objetivo do artigo é contribuir para a compreensão das relações entre o enriquecimento geoquímico das águas fluviais da borda oeste da Serra do Cipó, porção sul da Serra do Espinhaço Meridional, e a configuração geomorfológica das zonas de cabeceira de drenagem, incluindo nascentes e cursos fluviais de $1^{\mathrm{a}}$ e $2^{\mathrm{a}}$ ordens. Para tanto, foram estudadas duas bacias hidrográficas de $2^{\mathrm{a}}$ ordem na área do Parque Nacional da Serra do Cipó e da Área de Proteção Ambiental Morro da Pedreira. Os resultados podem contribuir para a compreensão da evolução do relevo regional.

\section{2. Área de estudos}

As bacias de $2^{\mathrm{a}}$ ordem estudadas situam-se na borda oeste da Serra do Cipó, uma subunidade da porção sul da Serra do Espinhaço situada a cerca de $100 \mathrm{~km}$ de Belo Horizonte (Figura 1).

A Serra do Espinhaço Meridional se estrutura como faixa dobrada sustentada principalmente por espesso pacote metassedimentar do Supergrupo Espinhaço (SAADI, 1995). A Serra exerce o papel regional de unidade morfológica cimeira, atuando como 
divisor entre as bacias dos rios São Francisco (oeste), Jequitinhonha (nordeste) e Doce (sudeste). A borda oeste da Serra marca a zona de contato entre a Serra do Espinhaço e a Depressão do Alto-Médio São Francisco, modelada em rochas sedimentares neoproterozoicas metamorfizadas durante os processos de (de)formação da cadeia do Espinhaço, com aumento progressivo da influência tectônica para leste (UHLEIN et al., 1995). Neste sentido, a borda oeste da Serra do Espinhaço se configura em uma zona deformada pelos movimentos de empurrão da macroestrutura do Espinhaço sobre as rochas do Grupo Bambuí que foram, em parte, dobradas.

\section{LOCALIZAÇÃO DAS BACIAS EM ESTUDO Serra do Cipó - MG}
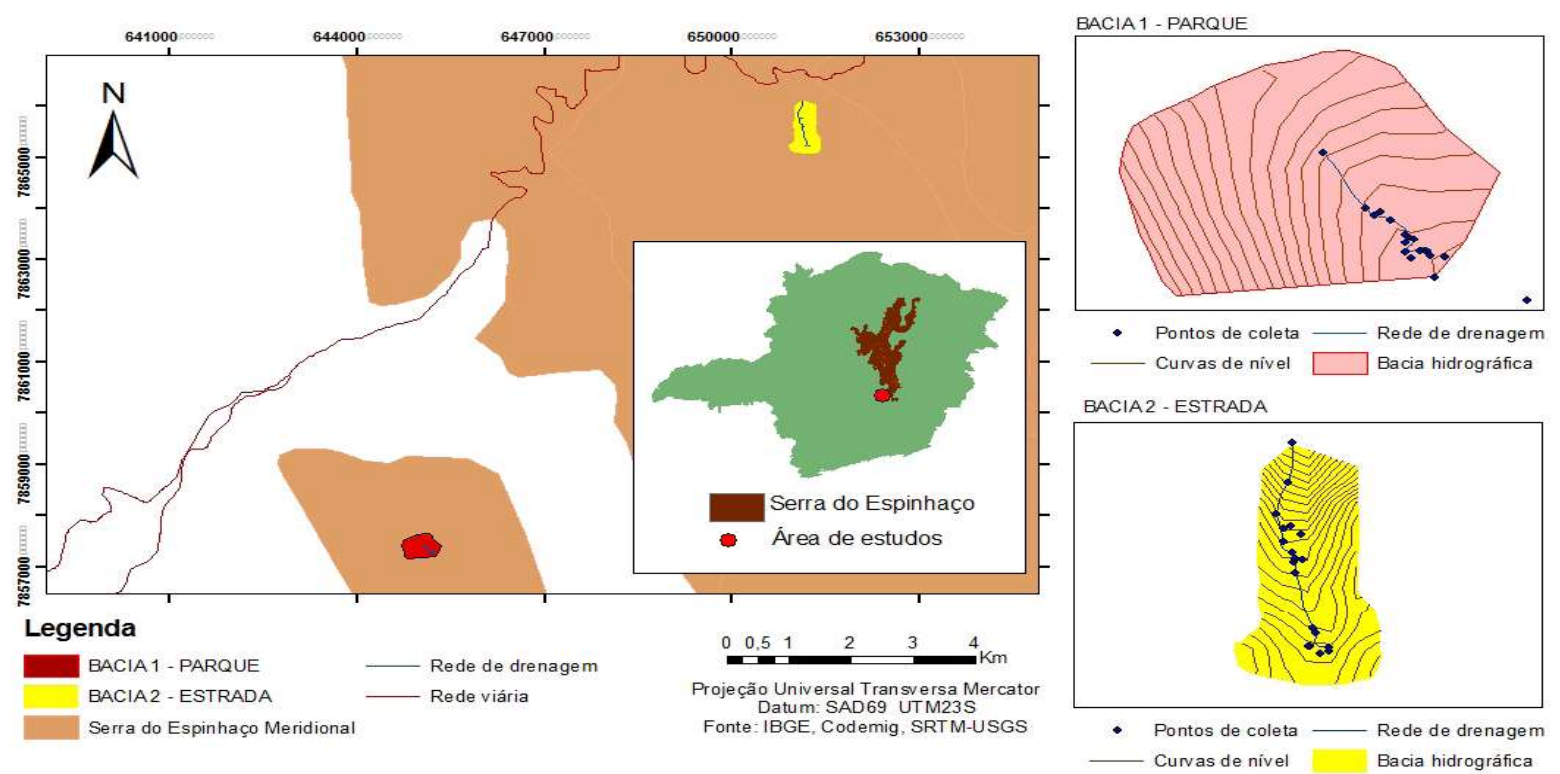

Figura 1 - Localização das bacias estudadas

Esta unidade de relevo é modelada principalmente em rochas metassedimentares glaciogênicas neoproterozóicas do Grupo Macaúbas, com destaque para metadiamictitos, quartzitos e metassiltitos (ALMEIDAABREU e RENGER, 2002). Estas rochas estão em contato com as do Grupo Conselheiro Mata, no topo da sequência do Supergrupo Espinhaço. A Serra apresenta uma sequência litológica de rochas oriundas de depósitos marinhos rasos, principalmente quartzitos, filitos e metaconglomerados (CHEMALE JÚNIOR et al., 2011).

A unidade litológica com maior representatividade espacial na Serra do Espinhaço Meridional é a Formação Galho do Miguel, em contato com o Grupo Conselheiro Mata. É formada essencialmente por espessos quartzitos puros e finos de origem eólica que podem atingir $3000 \mathrm{~m}$ de profundidade (ALMEIDA-ABREU, 1995). Devido à sua resistência aos processos de meteorização, estes quartzitos sustentam as cristas e superfícies cimeiras da Serra do Cipó (SALGADO; VALADÃO, 2003). A diversidade geológica regional resulta em rico e complexo quadro hidrogeológico que condiciona os processos de desnudação geoquímica e as características das águas subterrâneas e superficiais.

A Serra do Cipó configura-se como um maciço planáltico orientado genericamente no sentido NW$\mathrm{SE}$, com morfologia de cristas entrecortadas por vales fluviais com elevado grau de dissecação (FELIPPE; MAGALHÃES JR, 2016). A morfologia dissecada e os vales encaixados estão, muitas vezes, associados a escarpas de falha que coincidem com as principais frentes de cavalgamento identificadas por AlmeidaAbreu (1995). Por sua vez, as bordas do planalto apresentam trechos com escarpas erosivas modeladas a partir da resistência litológica diferencial.

Ambas as bacias de $2^{\mathrm{a}}$ ordem situam-se em áreas com abundância de afloramentos rochosos e formações superficiais rasas e arenosas. Entretanto, há porções 
localizadas de solos profundos, principalmente na bacia situada no Parque Nacional da Serra do Cipó. Há estreita relação entre os substratos litológicos e as coberturas pedológicas (FELIPPE, 2013), predominando Neossolos Litólicos, Neossolos Quartzarênicos e Espodossolos nas áreas de quarzitos e metadiamictitos,

A respeito da vegetação, a Serra do Cipó apresenta predomínio de campos rupestres e cerrado (IEF, 2009). Conforme o IBGE (2002) o clima local é sub-quente semiúmido, com temperaturas médias entre 15 e $18^{\circ} \mathrm{C}$ e 4 a 5 meses secos. A média de precipitação anual é de $1500 \mathrm{~mm}$, com um período de excedente hídrico entre novembro a março e um déficit entre abril e setembro. Há, portanto, um claro quadro de estacionalidade climática.

O Rio Cipó, formado pelo encontro dos rios Bocaína (direção E-W) e Mascates (S-N) é o principal curso d'água que drena a Serra do Cipó. O Rio Cipó corre paralelo à Serra no eixo sul-norte até desaguar no Rio das Velhas, um dos principais afluentes do Rio São Francisco. A rede hidrográfica tem expressivo condicionamento estrutural, com frequentes segmentos retilíneos e bruscas mudanças de direção que refletem os lineamentos do substrato rochoso deformado. A bacia A apresenta área de $232.317 \mathrm{~m}^{2}$ e está inserida no Parque Nacional da Serra do Cipó, sendo integrante da Bacia do Córrego do Capão, afluente do Rio Mascates. A bacia B possui área de $387.341 \mathrm{~m}^{2}$ e situa-se próxima ao trecho da MG010 que passa pelo distrito de Serra do Cipó, na APA Morro da Pedreira. Esta bacia apresenta um curso d'água principal sem denominação oficial, o qual deságua na margem direita do Rio Cipó à jusante do referido distrito.

A bacia A possui forma relativamente circular e assimétrica, com interflúvio nas cristas quartzíticas do Grupo Macaúbas. O curso d'água principal é bem marcado e encaixado, mas apresenta afluentes de $1^{\mathrm{a}}$ ordem com incisão incipiente a baixa. Os solos bem drenados e arenosos são intercalados por manchas de materiais mais argilosos e, aparentemente, com maior presença de matéria orgânica. Estão associados, sobretudo, à maior proximidade do nível freático, formando pequenas e suaves depressões onde, muitas vezes, ocorrem nascentes. Deste modo, os canais de $1^{\mathrm{a}}$ ordem possuem segmentos efêmeros e intermitentes bem caracterizados e que variam com a sazonalidade do nível freático.
Por sua vez, a bacia B ocorre em um dos patamares mais elevados da Serra do Cipó, modelada nos quartzitos Galho do Miguel. A bacia possui formato alongado com vertentes mais retilíneas em relação às da bacia A. Ocorrem vastos afloramentos de quartzitos e predominam solos rasos e extremamente arenosos. Porém, na porção mais à montante da bacia, há uma mancha de solos avermelhados mais profundos, onde ocorrem nascentes. Essa mancha parece derivar de uma intrusão de rochas básicas, muito comum na Serra (CHEMALE JR et al., 2011).

\section{Materiais e métodos}

Em campo foram coletadas amostras de água para análise de Sólidos Totais Dissolvidos (TDS) e de parâmetros auxiliares: sílica, alcalinidade e condutividade elétrica. A seleção dos parâmetros foi realizada buscando-se levar em consideração as características hidrogeológicas locais, assim como as recomendações de Feitosa e Manoel-Filho (2000), Hindi et al. (2003) e Salgado e Valadão (2003) para estudos de perdas geoquímicas.

Os pontos de coleta das amostras de água foram pré-determinados segundo a hierarquia fluvial, contemplando nascentes (ordem 0) e canais de $1^{\mathrm{a}} \mathrm{e}$ $2^{a}$ ordens em duas bacias: uma no interior do Parque Nacional da Serra do Cipó (bacia A; Figuras 2 e 3) e outra próxima ao trecho da MG010 que passa pelo município de Santana do Riacho (bacia B; Figuras 4 e 5). A escolha obedeceu à verificação da possibilidade de reconstituição da rede de drenagem em campo, com identificação das nascentes e das confluências que confirmassem a configuração de bacias de $2^{\mathrm{a}}$ ordem. Deste modo, ficou confirmada a possibilidade de acesso para coletas de água nas nascentes e nos cursos d'água.

Ao contrário da componente física da desnudação, em que há importantes dificuldades metodológicas de monitoramento e avaliação, as perdas geoquímicas podem ser mais facilmente mensuradas a partir das concentrações minerais em amostras de água. Por isto, os estudos geomorfológicos sobre o tema em meio tropical têm se concentrado nesta abordagem.

As amostras foram analisadas no Laboratório de Geomorfologia da UFMG (Universidade Federal de Minas Gerais), seguindo criteriosamente as normas do Standard Methods for Examination of Water and Wastewater (APHA; AWWA; WEF, 2012). 
Posteriormente, foi realizada a análise estatística, organização e tabulação dos dados, produção de gráficos e interpretação. Seis trabalhos de campo foram realizados em novembro de 2015 , março, junho e setembro de 2016 , e fevereiro e junho de 2017 , abarcando as estações úmida e seca e permitindo comparações entre os regimes anuais. Em novembro de 2016 o monitoramento não pôde ser realizado.

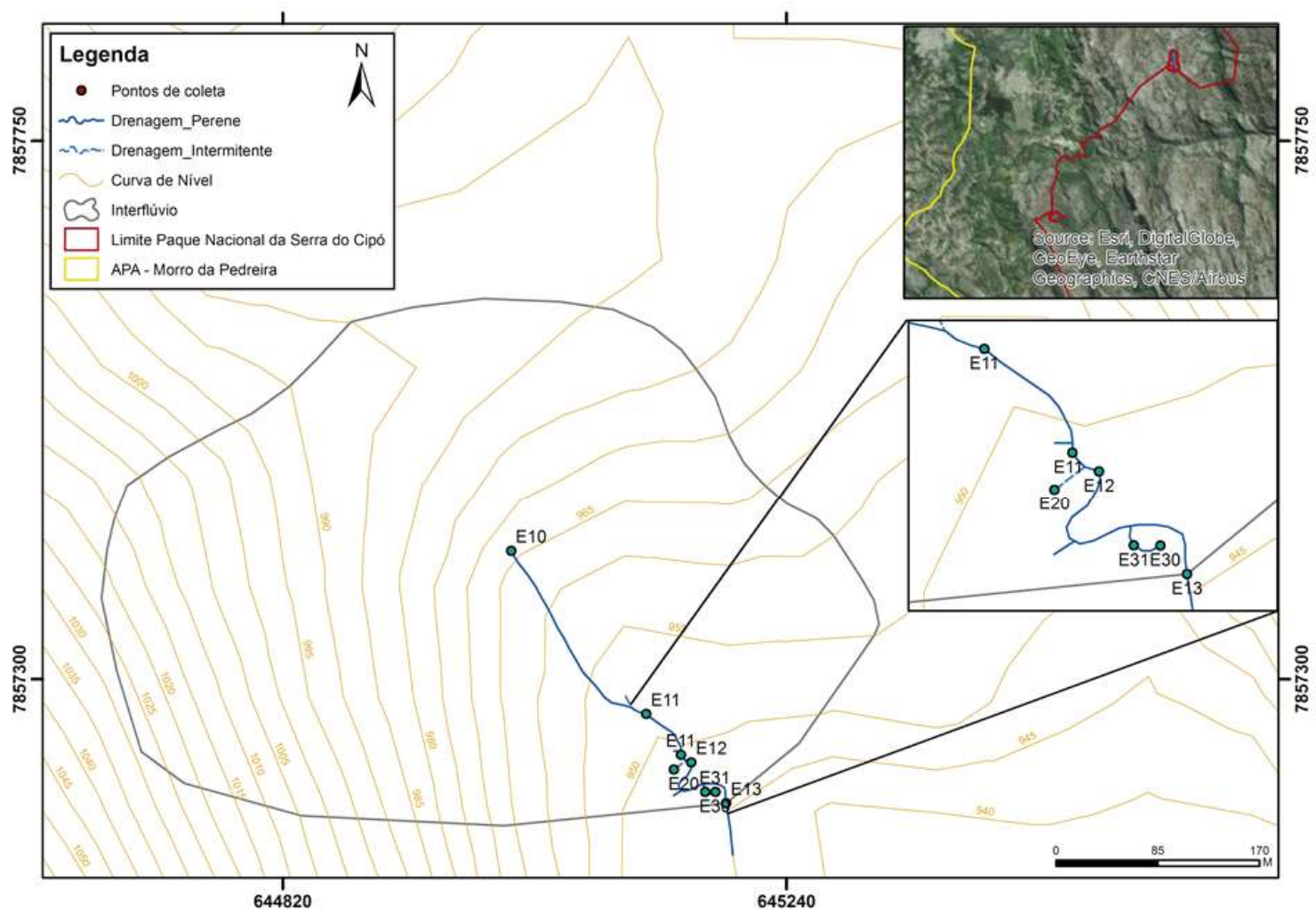

Figura 2 - Bacia A - Parque Nacional da Serra do Cipó

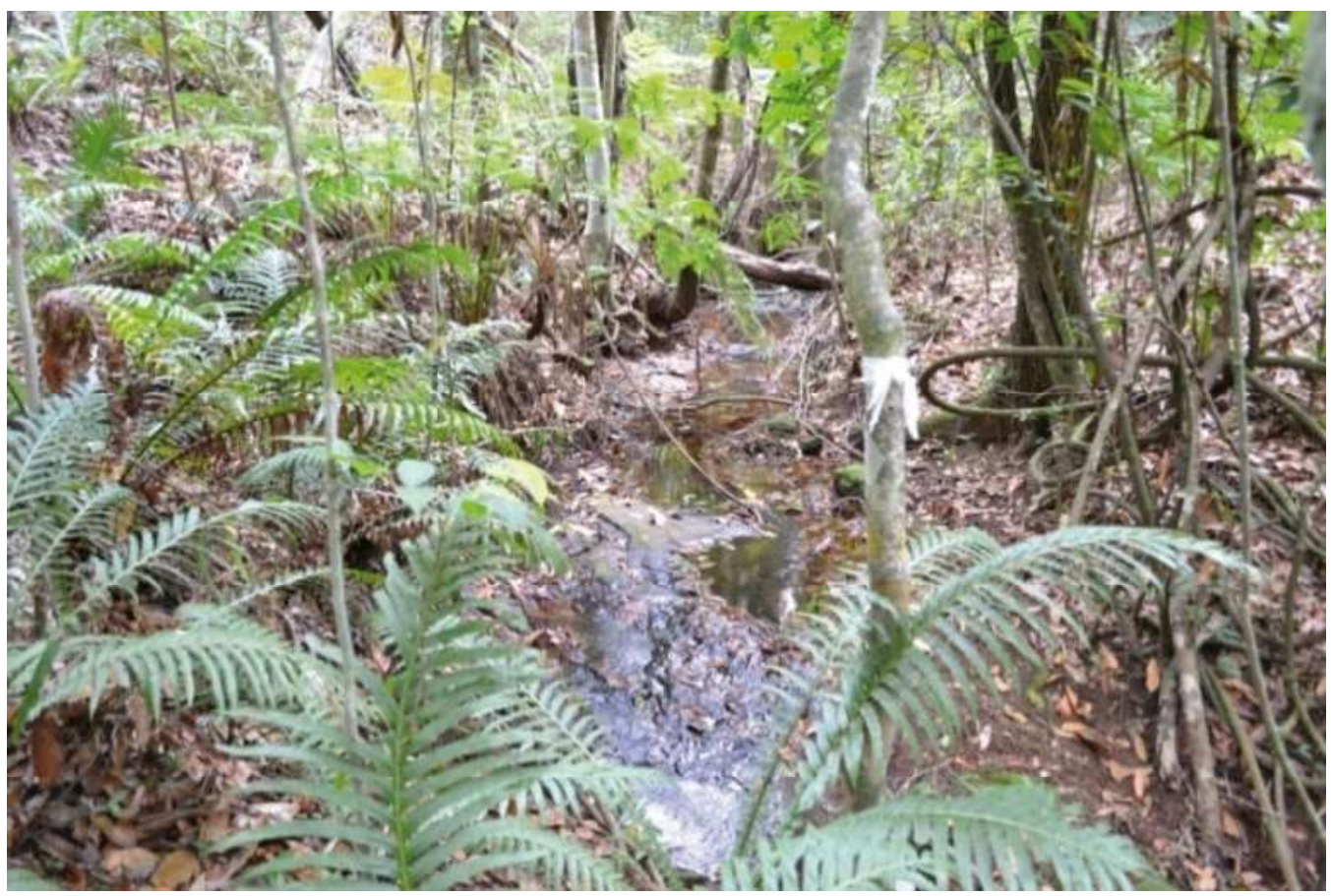

Figura 3 - Contexto fisiográfico da bacia A 


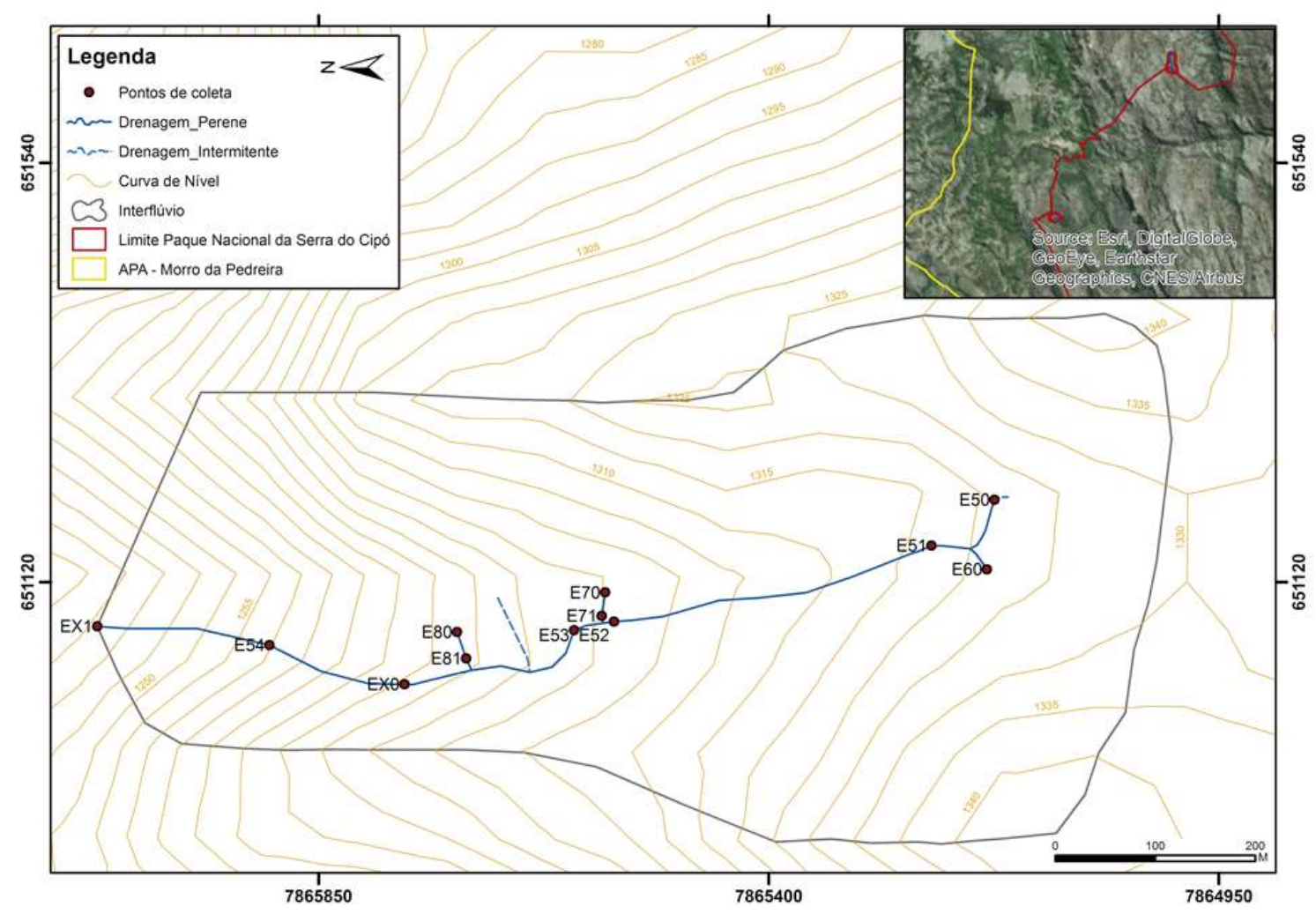

Figura $4-$ Bacia B

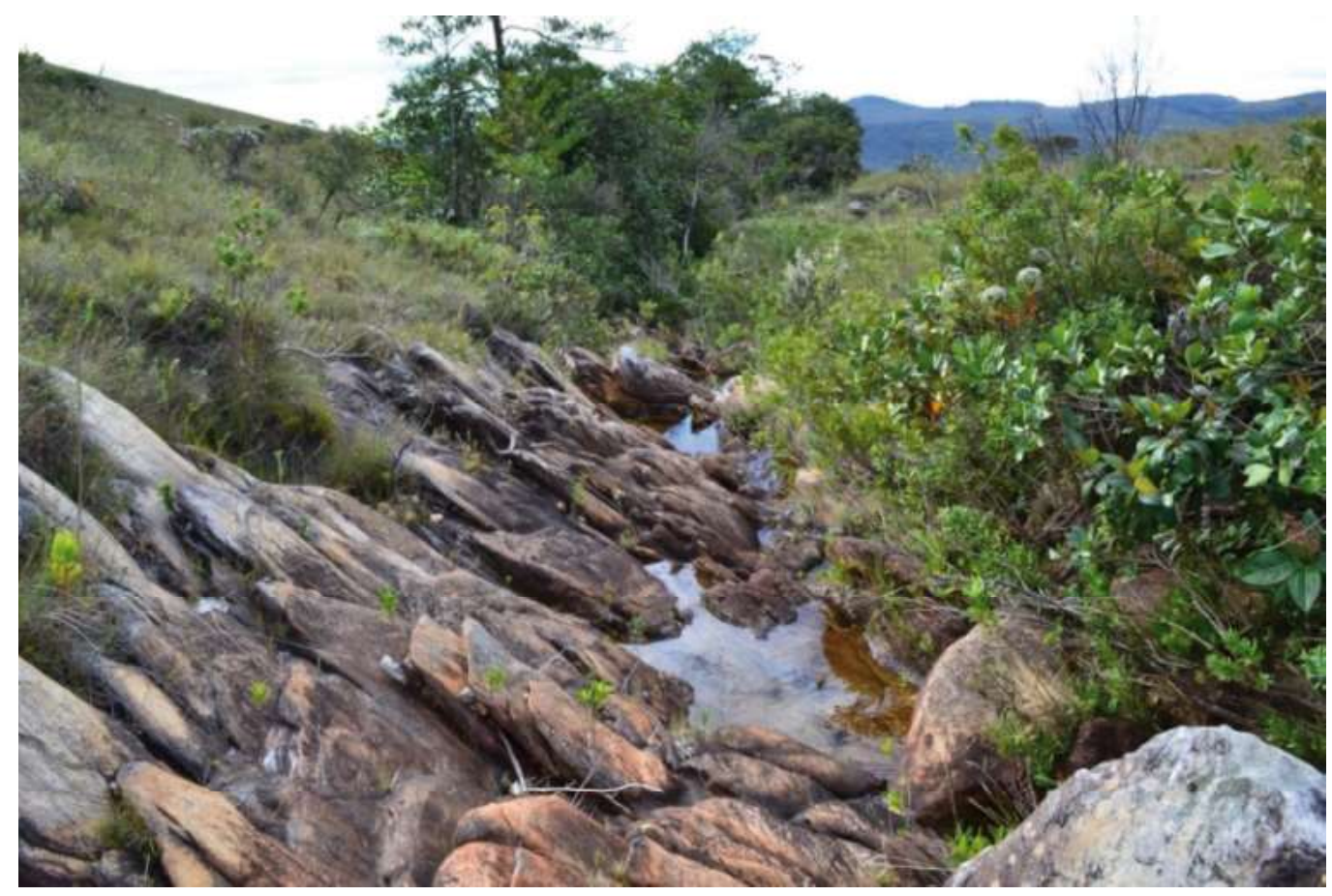

Figura 5 - Contexto fisiográfico da bacia $B$

O TDS foi calculado pela técnica da Gravimetria com amostras filtradas, a partir da diferença de massa antes e após evaporação em estufa a $180^{\circ} \mathrm{C}$ durante
24 horas (ou até a secagem completa da capsula), com alíquotas de $100 \mathrm{~mL}$. As análises de TDS foram realizadas em duplicatas. 
A sílica foi determinada pela técnica de espectrofotometria na região do visível. O produto formado pela reação da sílica com o Molibdato de Amônio em $\mathrm{pH}=1,2$ forma um complexo de coloração amarelada que é lida em 410nm. A intensidade da cor é proporcional à concentração do composto na amostra (APHA; AWWA; WEF, 2012). O cálculo da concentração foi feito por meio da equação da reta obtida na curva de calibração. Foram preparados cinco padrões de $\mathrm{SiO}_{2}$ com concentrações de 2, 5, 10, 20 e $30 \mathrm{mg} / \mathrm{L}$ e realizadas as leituras em espectrofotômetro TECNAL V-5000, a $410 \mathrm{~nm}$. Os dados da leitura em absorvância versus concentração do padrão em $\mathrm{mg} / \mathrm{L}$ foram plotados num gráfico obtendo-se uma linha da tendência de correlação entre as variáveis $(r=0,9969)$ e a sua respectiva equação.

A alcalinidade foi obtida a partir da amostra filtrada (filtros de $0,45 \mu \mathrm{m}$ ) por titulação potenciométrica em titulador automático HANNA H1902 utilizando como titulante o HCL $0,1 \mathrm{M}$ padronizado. A condutividade foi mensurada em laboratório a partir da amostra não filtrada utilizando-se um condutivímetro MS TECNOPOM mCa150. A célula de condutividade com constante $\mathrm{k}=0,1$ é adequada para medida de soluções pouco concentradas aplicando-se precisamente na determinação desse parâmetro nas amostras coletadas em campo. As amostras foram armazenadas, sob refrigeração, em recipientes plásticos de $500 \mathrm{~mL}$, sem acidificação.

A análise e interpretação dos resultados laboratoriais foram realizadas por ponto amostral, situação no ano hidrológico e hierarquia fluvial em cada bacia. Também contou com a análise das médias por teste a cada campanha de campo, desconsiderando-se outliers e buscando visualizar a oscilação global dos dados. A tabulação e organização dos dados foram realizadas com o auxílio do software Excel, assim como a produção de gráficos como ferramenta para análise e interpretação dos dados.

Dados de vazão foram medidos para contribuir com as interpretações sobre as concentrações geoquímicas e sobre a dinâmica hídrica local. Dadas às baixas vazões dos pontos de amostragem, foi empregada a técnica de enchimento cronometrado de bolsas de plástico devidamente ajustadas à morfologia dos leitos. Foi realizada a média de três medidas de cada ponto de mensuração. As vazões também foram relacionadas com dados de precipitação obtidos da base do grupo PELD - Pesquisas Ecológicas de Longa Duração, sediado no Instituto de Ciências Biológicas da Universidade Federal de Minas Gerais. Os dados equivalem ao período entre outubro de 2016 a março de 2017, sendo priorizadas estações próximas às bacias estudadas e situadas nas cotas de $800 \mathrm{~m}$, para a bacia A, e $1300 \mathrm{~m}$ para a bacia B. Estas estações serão referidas como $1 \mathrm{e}$ 2 , respectivamente.

Para a análise da forma das bacias foi aplicado o Índice de Circularidade (Ic) conforme a fórmula (TUCCI, 2000):

$$
\mathrm{Ic}=12,57 \times \mathrm{A} / \mathrm{P}^{2}
$$

em que A é a área $\mathrm{em} \mathrm{m}^{2} \mathrm{e} \mathrm{P}$ é o perímetro em $\mathrm{m}$.

O Índice de Circularidade tende para a unidade à medida que a bacia se aproxima da forma circular $\mathrm{e}$ diminui à medida que a forma é alongada.

\section{Resultados e Discussão}

Os resultados laboratoriais revelam tendências que contribuem para a análise da mineralização das águas e das perdas geoquímicas dos maciços rochosos da área. $\mathrm{O}$ estado de atividade dos pontos de exfiltração refletiu a forte sazonalidade pluviométrica local. Quase todos os pontos da bacia A estiveram ativos durante todo o período analisado, mas a bacia B esteve totalmente seca em novembro de 2015 e com poucos pontos ativos em junho e setembro de 2016 (estação seca e início da estação úmida). Em março e fevereiro de 2016 (final da estação úmida), praticamente todos os pontos estavam ativos. Aúnica nascente perene ao longo dos seis períodos de monitoramento foi a E10 (Bacia A), apesar da sua considerável migração de mais de $150 \mathrm{~m}$ de montante para jusante. A dinâmica e a atividade dos pontos de monitoramento refletem diretamente o regime pluviométrico na área estudada (Figura 6). Os dados de precipitação acumulada foram muito próximos entre as bacias, com maiores diferenças entre novembro de 2016 e fevereiro de 2017 (Figura 7).

Os valores dos parâmetros geoquímicos variaram ao longo do ano hidrológico analisado (Tabela 1). Excetuando-se os casos de dados abaixo dos limites de detecção, os valores de TDS variaram entre 4 e $87 \mathrm{mg} / 1$ nas duas bacias (Tabela 2). Na bacia A, houve casos de redução dos valores de TDS entre março e junho de 2016 (E10, E12), mas também de aumento (E11). Já em setembro do mesmo ano, todos os pontos com fluxos ativos apresentaram aumento significativo, refletindo os efeitos da estação seca. O aumento chegou a 737\% no ponto E12 e $510 \%$ no ponto E13. Nas nascentes, a elevação foi de $216 \%$ na E10, $287 \%$ na E20, e $375 \%$ na E30 (Tabela 2). Entre fevereiro e junho de 2017 houve queda significativa dos valores em todos os pontos ativos (por volta de $100 \%$ ). 
Tabela 1: Resultados dos parâmetros geoquímicos por ponto de monitoramento

\begin{tabular}{|c|c|c|c|c|c|c|c|c|c|c|c|c|c|c|c|c|c|c|c|c|c|c|c|c|c|}
\hline \multirow{2}{*}{ Amostra $^{2}$} & \multirow{2}{*}{ Hierarquia } & \multicolumn{6}{|c|}{ TDS GRAVIMÉTRICO (mgL) } & \multicolumn{6}{|c|}{ ALCALINIDADE (mg $\mathrm{L}$ de $\mathrm{CaCO} 3$ ) } & \multicolumn{6}{|c|}{ CONDUTIVIDADE $(\mu \mathrm{s} / \mathrm{cm})$} & \multicolumn{6}{|c|}{ SiLICA $(m g /)$} \\
\hline & & nov/15 & $\operatorname{mar} 16$ & jun/16 & set/16 & fev/17 & jun 01 & nov/15 & $\operatorname{mar} 16$ & jun/16 & set 16 & fer/17 & jun/01 & nov/15 & $\operatorname{mar} 16$ & jun/16 & set 16 & fer/17 & \begin{tabular}{|l|l|}
$j u n / 01$ \\
\end{tabular} & nov/15 & $\operatorname{mar} 116$ & jun/16 & set 16 & fev/17 & jun/01 \\
\hline E10 & 0 & 0 & 31 & 24 & 76 & 39 & 19 & 3,5 & 4,5 & 3 & 4 & 3,5 & 11 & 3,59 & 7,35 & 3,95 & 8,34 & 8,00 & 14,91 & & & 1,51 & 7,96 & 2,61 & 6,50 \\
\hline E11 & 1 & 0 & 6 & 21 & 52 & 45 & 13 & 5 & 5 & 3,5 & 4 & 4 & 7,5 & 8,58 & 6,05 & 4,82 & 4,65 & 15,39 & 4,93 & & & 2,43 & 7,74 & 2,93 & 6,69 \\
\hline E12 & 2 & -2 & 12 & 8 & 67 & 54 & 5 & - & 5 & 3,5 & 4 & 4 & 6,5 & - & 3,55 & 2,74 & 6,62 & 7,58 & 3,27 & & & 2,42 & 6,9 & 3,66 & 6,59 \\
\hline E20 & 0 & 30 & 6 & 16 & 62 & 35 & - & 5,5 & 3 & 2,5 & 3 & 2,5 & - & 5,29 & 5,37 & 6,66 & 6,8 & 10,0 & - & & & 1,5 & 7,92 & 3,43 & - \\
\hline E21 & 1 & - & 13 & - & - & - & - & - & 2,5 & - & - & 2 & - & - & 6,28 & - & - & 14,0 & - & & & - & - & 3,94 & - \\
\hline $\mathrm{E} 30$ & 0 & 20 & 15 & 8 & 38 & 73 & 12 & 6,5 & 3,5 & 3 & 3 & 3 & 6 & 6,74 & 6,35 & 6,86 & 6,64 & 9,82 & 6,48 & & & 4,25 & 9,34 & 6,00 & 8,15 \\
\hline E31 & 1 & 0 & 4 & 26 & 78 & 45 & 13 & 5 & 3,5 & 3 & 3 & 3 & 7,5 & 4,35 & 4,74 & 4,97 & 6,58 & 6,59 & 4,59 & & & 1,96 & 9,34 & 8,56 & 9,57 \\
\hline E50 & 0 & 0 & 11 & 38 & 40 & 60 & 6 & 5 & 3 & 3 & 4 & 3 & 4 & 3,2 & 5,05 & 5,9 & 2,9 & 5,93 & 4,88 & & & 0,13 & 7,87 & 0,50 & 4,12 \\
\hline E51 & 1 & 0 & 12 & 18 & 56 & 77 & 0 & 5,5 & 3 & 4 & 4 & 3 & 3 & 4,21 & 4,03 & 2,68 & 3,55 & 7,24 & 2,75 & & & 0 & 8,38 & 0,50 & 4,76 \\
\hline E52 & 2 & - & 13 & 50 & $\cdot$ & 87 & 12 & - & 3,5 & 4 & - & 3 & 4 & - & 3,58 & 2,73 & . & 4,64 & 3,19 & & & 0 & . & 1,69 & 7,60 \\
\hline E60 & 0 & - & 20 & - & - & 74 & - & - & 3 & - & - & 3 & - & - & 5,45 & - & - & 4,93 & - & & & - & - & 2,06 & - \\
\hline E70 & 0 & - & 17 & - & $\therefore$ & 31 & - & - & 0,5 & - & - & 1,5 & - & - & 12,23 & - & - & 12,93 & - & & & - & - & 0 & - \\
\hline E71 & 1 & - & 23 & - & - & 48 & - & . & 1 & - & - & 1,5 & - & - & 10,03 & - & - & 11,92 & - & & & - & - & 0 & - \\
\hline E8O & 0 & - & 28 & 70 & - & 37 & 24 & - & 2 & 2 & - & 2 & 3 & - & 8,88 & 14,0 & - & 12,31 & 9,65 & & & 2,88 & - & 5,22 & 7,65 \\
\hline E81 & 1 & - & 23 & - & - & - & - & - & 2 & - & - & - & - & - & 7,83 & - & - & - & - & & & - & - & - & - \\
\hline
\end{tabular}

Obs.: ${ }^{1}$ Os algarismos finais das amostras representam a hierarquia fluvial: 0 -nascentes; 1 -curso d'água de $1^{a}$ ordem; 2 -curso d'água de $2^{a}$ ordem; 3 - os dados de sílica só foram medidos a partir de junho/2016. ${ }^{2}$ Os campos marcados com “- " representam ausência de fluxos no período em questão (ponto seco). ${ }^{3}$ Linhas em branco correspondem à bacia A e linhas em cinza correspondem à bacia B.

Tabela 2: Evolução Percentual do TDS entre os períodos de monitoramento

\begin{tabular}{|c|c|c|c|c|c|c|c|c|c|c|c|c|c|c|}
\hline \multirow[b]{2}{*}{$\begin{array}{c}\text { Ponto de } \\
\text { coleta } \\
\text { (código) }\end{array}$} & \multirow[b]{2}{*}{$\begin{array}{c}\text { Posição na } \\
\text { rede de } \\
\text { drenagem }\end{array}$} & \multicolumn{2}{|c|}{ nov/15 } & \multicolumn{2}{|c|}{$\mathrm{mar} / 16$} & \multicolumn{2}{|c|}{ jun/16 } & \multicolumn{2}{|c|}{ set/16 } & \multicolumn{2}{|c|}{ fev/17 } & \multicolumn{2}{|c|}{ jun/17 } & \multirow[b]{2}{*}{$\begin{array}{l}\text { Valor médio } \\
\text { do ponto } \\
\text { (entre os } 4 \\
\text { períodos) }\end{array}$} \\
\hline & & Valor & $\begin{array}{l}\text { Evolução } \\
{ }^{1}(\%)\end{array}$ & Valor & $\begin{array}{l}\text { Evolução } \\
(\%)\end{array}$ & Valor & $\begin{array}{l}\text { Evolução } \\
(\%)\end{array}$ & Valor & $\begin{array}{l}\text { Evolução } \\
(\%)\end{array}$ & Valor & $\begin{array}{l}\text { Evolução } \\
(\%)\end{array}$ & Valor & $\begin{array}{l}\text { Evolução } \\
(\%)\end{array}$ & \\
\hline E10 & Nascente & 0 & - & 31 & & 24 & $-22,58 \%$ & 76 & $216,67 \%$ & 39 & $-48,68 \%$ & 19 & $-51 \%$ & 31,5000 \\
\hline E11 & 1a ordem & 0 & - & 6 & & 21 & $250,00 \%$ & 52 & $147,62 \%$ & 45 & $-13,46 \%$ & 13 & $-71 \%$ & 22,8333 \\
\hline E12 & 2a ordem & & - & 12 & - & 8 & $-33,33 \%$ & 67 & $737,50 \%$ & 54 & $-19,40 \%$ & 5 & $-91 \%$ & 24,3333 \\
\hline E20 & Nascente & 30 & - & 6 & $-80,00 \%$ & 16 & $166,67 \%$ & 62 & $287,50 \%$ & 35 & $-43,55 \%$ & & & 29,8000 \\
\hline E21 & 1ㅇo ordem & & - & 13 & - & & - & & - & & - & & & 13,0000 \\
\hline E30 & Nascente & 20 & - & 15 & $-25,00 \%$ & 8 & $-46,67 \%$ & 38 & $375,00 \%$ & 73 & $92,11 \%$ & 12 & $-84 \%$ & 27,6667 \\
\hline E31 & 1a ordem & 0 & - & 4 & & 26 & $550,00 \%$ & 78 & $200,00 \%$ & 45 & $-42,31 \%$ & 13 & $-71 \%$ & 27,6667 \\
\hline $\mathrm{E} 50$ & Nascente & 0 & - & 11 & - & 38 & $245,45 \%$ & 40 & $5,26 \%$ & 60 & $50,00 \%$ & 6 & $-90 \%$ & 31,0000 \\
\hline E51 & 1a ordem & 0 & - & 12 & - & 18 & $50,00 \%$ & 56 & $211,11 \%$ & 77 & $37,50 \%$ & 0 & $-100 \%$ & 32,6000 \\
\hline E52 & 2a ordem & & - & 13 & - & 50 & $284,62 \%$ & & - & 87 & - & 12 & $-86 \%$ & 40,5000 \\
\hline $\mathrm{E} 60$ & Nascente & & - & 20 & - & & - & & - & 74 & - & & & 47,0000 \\
\hline E70 & Nascente & & - & 17 & - & & - & & - & 31 & - & & & 24,0000 \\
\hline E71 & 1a ordem & & - & 23 & - & & - & & - & 48 & - & & & 35,5000 \\
\hline E80 & Nascente & & - & 28 & - & 70 & $150,00 \%$ & & - & 37 & - & 24 & $-35 \%$ & 39,7500 \\
\hline E81 & 1a ordem & & - & 23 & - & & - & & - & & & & & 23,0000 \\
\hline
\end{tabular}

Obs.: Os campos marcados com "-. "referem-se a ausência de fluxo no periodo de monitoramento anterior, o que impossibilita o cálculo de percentuais de variação. Os campos sem valores representam ausência de fluxos no período em questão (ponto seco). Os valores em negrito referem-se à percentuais de perda.

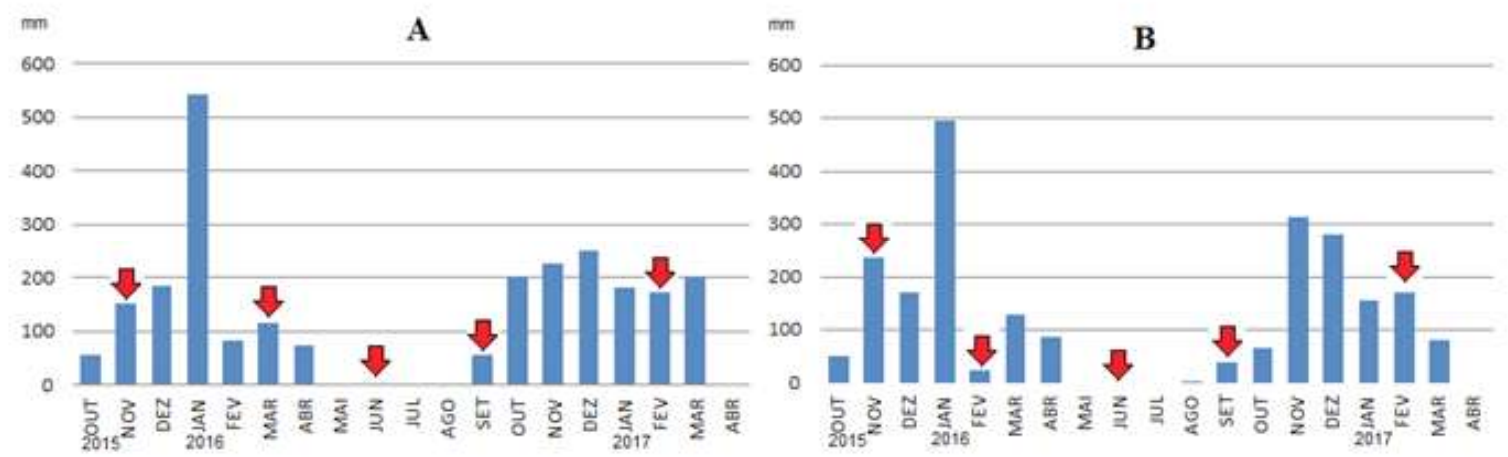

Figura 6-Totais mensais de precipitação. A-Estação pluviométrica situada próximo à bacia A (800 m de altitude); B-Estação pluviométrica situada próximo à bacia B (1.300 m de altitude). Fonte: Grupo PELD - Pesquisas Ecológicas de Longa Duração / ICB-UFMG. As setas em vermelho indicam o período de realização das coletas de campo. 


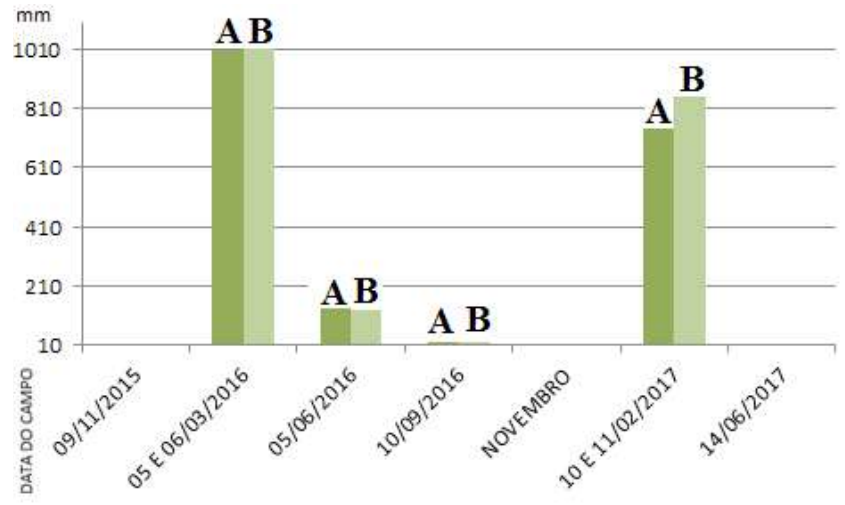

Figura 7-Acumulados de precipitação entre os periodos de monitoramento. $A$-Estação pluviométrica situada próximo à bacia A $(800$ $m$ de altitude); $B$ - Estação pluviométrica situada próximo à bacia $B$ (1.300 m de altitude). Fonte: Grupo PELD - Pesquisas Ecológicas de Longa Duração / ICB-UFMG.

A bacia B estava praticamente seca em novembro de 2015, com uma tendência geral de aumento das concentrações entre março e setembro nos pontos ativos. Entre março e junho os valores de TDS apresentaram uma elevação importante, em termos gerais. Nas duas nascentes ativas em junho, o aumento foi de $245,5 \%$ na E50 e de $150 \%$ na E80. Em setembro, os valores aumentaram pouco na nascente E50 em relação a junho (5, \%), mas bastante no ponto E51 (211,1\%). Estes foram os únicos pontos com fluxos ativos na bacia $\mathrm{B}$, neste mês. A nascente E50 e o ponto E51 apresentaram elevação do TDS em fevereiro de 2017 com relação a setembro de 2016. Os valores se situaram entre $12 \mathrm{e}$ $77 \mathrm{mg} / 1$ na bacia $\mathrm{B}$, mas com um número bem inferior de dados do que a bacia $\mathrm{A}$ em função da frequência de pontos secos ao longo do período analisado. Em junho de 2017 verificou-se a mesma tendência da Bacia A: redução superior a $70 \%$ do TDS em praticamente todos os pontos ativos.

Em termos gerais, os valores foram marcadamente mais elevados em setembro de 2016, principalmente na bacia A, e bem mais baixos em junho de 2017. Em setembro, totais de 4,8 e $9 \mathrm{~mm}$ de chuvas foram registrados no dia anterior à coleta nas estações pluviométricas 1 e 2, respectivamente. Apesar de ter chovido mais na bacia $\mathrm{B}$, somente dois pontos de coleta estavam ativos, enquanto na bacia $\mathrm{A}$ este número sobe para sete. Entretanto, deve-se ressaltar que, apesar da coincidência das chuvas no dia anterior às coletas, o monitoramento de setembro foi realizado em meio a um longo período seco. As precipitações acumuladas entre
05 de junho e 10 de setembro de 2016 foram de apenas 11,2 e $16,8 \mathrm{~mm}$ para as estações 1 e 2 , respectivamente. Deste modo, o quadro geológico-geomorfológico da bacia B deve gerar aquíferos com maiores exigências de recarga acumulada para que ocorram processos de exfiltração, em relação à bacia $\mathrm{A}$.

Em junho de 2017 a coleta foi realizada durante dias chuvosos, o que pode explicar os baixos valores de TDS. Entretanto, os autores do artigo ainda não tiveram acesso aos dados pluviométricos deste mês. Outro período de baixos valores foi março de 2016, no qual a maioria dos pontos de coleta estava ativa. As coletas de março coincidem com o intervalo temporal de maior volume de precipitação acumulada entre as campanhas de monitoramento, neste caso referente ao período entre 09 de novembro de 2015 e 05 de março de 2016. Foram verificados 1010,4 e 1016,4mm de precipitação acumulada nas estações 1 e 2 , respectivamente. Os baixos valores de TDS de março de 2016 refletem não apenas o elevado índice pluviométrico acumulado entre este período de monitoramento e a anterior, mas particularmente os valores de precipitação mensal acumulada de todo o período monitorado: $249,6 \mathrm{~mm}$ em dezembro de 2015 na bacia A, e $495 \mathrm{~mm}$ em janeiro de 2016 na bacia $B$.

Já em fevereiro de 2017, os dados de TDS apresentaram valores relativamente elevados em plena estação chuvosa, com alguns pontos superando, inclusive, os de períodos secos como junho e setembro de 2016 . Este comportamento seria anômalo se não fossem levados em consideração os elevados índice pluviométricos de janeiro de 2016 (543,6mm para a Bacia A e $495 \mathrm{~mm}$ para a Bacia B), muito superiores aos valores de janeiro de 2017 (182 mm e $157 \mathrm{~mm}$, respectivamente). Portanto, a relação entre TDS e índices pluviométricos se mantém, com valores mais reduzidos em fevereiro de 2016 devido aos elevados níveis de precipitação em relação aos outros períodos de monitoramento.

Se considerarmos o período entre novembro de 2016 (período em que não houve monitoramento) e fevereiro de 2017, a precipitação acumulada foi de 743,6 e 869,2 mm para as estações 1 e 2, respectivamente, sendo inferior, somente, à de março de 2016. Os dias 10 e 11 de fevereiro, dias das coletas, ocorreram em pleno período chuvoso. Comparando-se com os dados de setembro, os valores de TDS de fevereiro foram superiores nos pontos E13 e E30, na bacia A, e E50 e E51, na bacia B, ficando próximos nos pontos E11 e E12. 
Setembro marca o fim da estação seca e, por isso, somente dois pontos da bacia B estavam ativos em 2016, impedindo as comparações com os dados de TDS de fevereiro. Com a baixa recarga dos aquíferos, há menor taxa de mistura (água subterrânea/água meteórica) nas nascentes e um maior tempo de residência médio para as águas exfiltradas. Desse modo, com mais tempo de atuação dos processos geoquímicos e menor diluição pelas chuvas, a tendência é de valores de TDS mais elevados. Esta tendência é confirmada com os baixos valores verificados em novembro de 2015 , em plena estação chuvosa, na bacia A, enquanto a bacia B esteve praticamente seca neste período. Analisando-se os dados pluviométricos, verifica-se que entre 01 de outubro e o dia 10 de novembro de 2015, dia das coletas, ocorreu um acumulado de somente 63,2 e $56 \mathrm{~mm}$ de chuvas nas estações 1 e 2, respectivamente. Apesar de terem ocorrido eventos chuvosos dois dias antes das coletas, em ambas as bacias, a recarga dos aquíferos no início da estação chuvosa parece não ter sido suficiente ao ponto de ativar a rede de drenagem na bacia B.

Novamente percebe-se que o quadro geológicogeomorfológico da bacia $\mathrm{B}$ parece gerar aquíferos com maiores exigências de recarga acumulada para que ocorram processos de exfiltração, em relação à bacia A. Outro fator que deve influenciar nas diferenças de dinâmica hidrológica superficial é a forma das bacias. A bacia B apresenta-se mais alongada (Índice de Circularidade 0,63$)$ do que a bacia A $(0,89)$ (Tabela 3 ), devendo apresentar maior tempo de concentração das águas pluviais. Mesmo que este fator não influencie na recarga dos aquíferos e nos processos de exfiltração, pode influenciar na atividade hidrológica resultante dos aportes superficiais nos períodos chuvosos.

Tabela 3: Índice de Circularidade conforme Tucci (2000)

\begin{tabular}{l|c|c|c}
\hline & \multicolumn{1}{c}{$\mathrm{A}\left(\mathrm{m}^{2}\right)$} & $\mathrm{P}(\mathrm{m})$ & $\mathrm{IC}$ \\
\hline BACIA A & 232.317 & 1804,06 & 0,897252 \\
\hline BACIA B & 387.341 & 2778,10 & 0,630860 \\
\hline
\end{tabular}

Este cenário pode ter conexão com as características das zonas de recarga das bacias. Ambas apresentam relação estreita entre fatores vegetacionais e atividade hídrica. A bacia A possui grande extensão em estratos de floresta estacional semidecidual, enquanto a bacia $\mathrm{B}$ está em área de campos rupestres, majoritariamente, com porções pontuais de mata ciliar (Figura 8). Nos monitoramentos em períodos de seca, de menores vazões, a bacia A mostrou-se intensamente mais ativa que a bacia B. Nesta última, ocorreu maior atividade hídrica nas manchas de matas. De modo geral, percebe-se que nos períodos de estiagem há uma tendência de maiores vazões nas zonas de matas ciliares do que nas de campos rupestres, o que se reflete em maiores valores de TDS.

O comportamento dos valores de TDS em função da hierarquia fluvial apresentou indicativos importantes do condicionamento da geomorfologia superficial. Há casos em que os valores das nascentes são superiores aos dos canais de $1^{\mathrm{a}}$ e $2^{\mathrm{a}}$ ordens, e também o contrário. As nascentes tendem a traduzir de forma mais fidedigna as características das águas subterrâneas, possuindo, em tese, menor influência dos processos meteóricos e superficiais. Entretanto, esta tendência depende do tipo de nascente. Nascentes pontuais e múltiplas (FELIPPE, 2013; FELIPPE; MAGALHÃES, 2016) refletem mais diretamente as características dos aquíferos. Já as nascentes difusas se configuram como zonas de exfiltração em que a água permanece por um tempo relativamente estagnada na superfície até escoar para os canais de $1^{\mathrm{a}}$ ordem. Assim, acabam sofrendo influência das formações superficiais nas quais se acumulam e percolam.

Os processos de mineralização das águas superficiais parecem ocorrer no segmento entre a nascente E30 e o ponto E31 (bacia A). Os dados de TDS da E30 foram $69 \%$ e $51 \%$ inferiores aos do ponto E31, em junho e setembro de 2016, respectivamente. Em fevereiro de 2017, entretanto, a nascente E30 apresentou um aumento de 24,6 $\%$ em relação ao do ponto E31, indicando que os efeitos acumulados do período chuvoso permitiram um maior enriquecimento mineral subterrâneo da água, em relação aos efeitos da mineralização superficial. Quando o regime pluviométrico e a variação do nível freático são suficientes para manter ou expandir a zona saturada da nascente E30, a mineralização superficial é garantida pelo contato da água com a cobertura orgânica. Os ácidos orgânicos contribuem para a dissolução de minerais e o aumento do TDS.

Deste modo, surgem indicativos de que os valores de TDS tem relação direta com as formações superficiais locais, resultando em tendências distintas do esperado para o fim da estação chuvosa. A nascente E30 é difusa (FELIPPE, 2013; FELIPPE; MAGALHÃES, 2016), ocorrendo em uma zona de exfiltração suavemente côncava que forma um brejo com água relativamente estagnada $\mathrm{e}$ abundância de matéria orgânica. Neste sentido, a atuação de processos geoquímicos superficiais e a mobilização de 
elementos que tendem a aumentar o TDS é bem provável. Aágua coletada no ponto de saída desta zona difusa reflete, portanto, um aumento do TDS por reações químicas na cobertura superficial, e não por processos exclusivamente subterrâneos. No ponto E31, situado à jusante, o efeito da diluição das maiores vazões e o distanciamento da referida área úmida resultam em valor de TDS 61,6\% inferior ao da nascente, para o mesmo período, e $42,4 \%$ inferior ao do mesmo ponto em setembro de 2016.

Outro caso ilustrativo da relação entre nascente difusa e enriquecimento geoquímico superficial ocorre na E50, bacia B. Esta nascente e o ponto E51 apresentaram elevação do TDS em fevereiro de 2017 com relação a setembro de 2016. Em ambos os períodos, os valores da nascente foram $40 \%$ e $28 \%$ inferiores aos do ponto E51, indicando a preponderância do enriquecimento geoquímico superficial na estação úmida, quando o encharcamento da cobertura orgânica garante uma maior atividade geoquímica superficial. Entretanto, nos períodos secos a E50 migra para jusante e passa a ser do tipo pontual. Em junho de 2017, a E50 apresentou um valor de TDS $47 \%$ superior ao do E51, resultado do enriquecimento subterrâneo preponderante durante o período seco. A
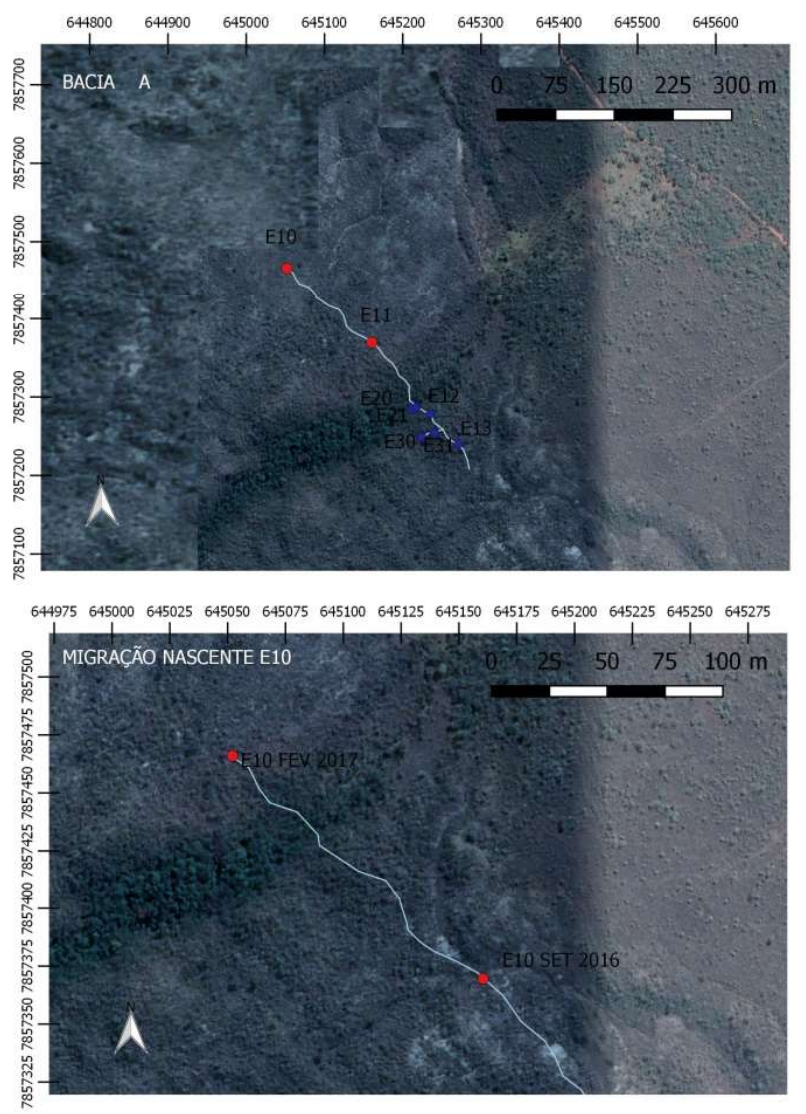

Figura 8 - Trechos de migração das nascentes E10 e E50 dinâmica da nascente E50 ilustra a sazonalidade hídrica acentuada da borda oeste da Serra do Cipó, com uma migração, de montante de para jusante, de cerca de 350 $m$ entre fevereiro e junho de 2017 (Figura 8). A dinâmica de migração dos processos de exfiltração pode, portanto, resultar na mudança da tipologia das nascentes.

Por sua vez, a nascente E10, na bacia A, ilustra os reflexos da sazonalidade na dinâmica de uma nascente pontual, tendo havido uma migração, de montante para jusante, de cerca de $150 \mathrm{~m}$ entre fevereiro de 2017 e setembro de 2016. Ao contrário da nascente E50, a nascente E10 manteve o seu caráter pontual entre os períodos úmido e seco, tendo migrado da zona de campo rupestre para a zona de floresta estacional semidecidual. A cobertura vegetal mais densa pode, deste modo, contribuir para os processos de conservação da umidade e exfiltração.

Esta migração das nascentes E50 e E10 deve-se ao rebaixamento dos níveis freáticos que as alimentam. Deste modo, o nível freático pode posicionar-se em camadas litológicas de constituição distinta, gerando reflexos na composição geoquímica das águas que exfiltram. Tais processos foram verificados em outros pontos da rede de drenagem, particularmente na bacia $\mathrm{B}$, conforme mostra a Figura 8.
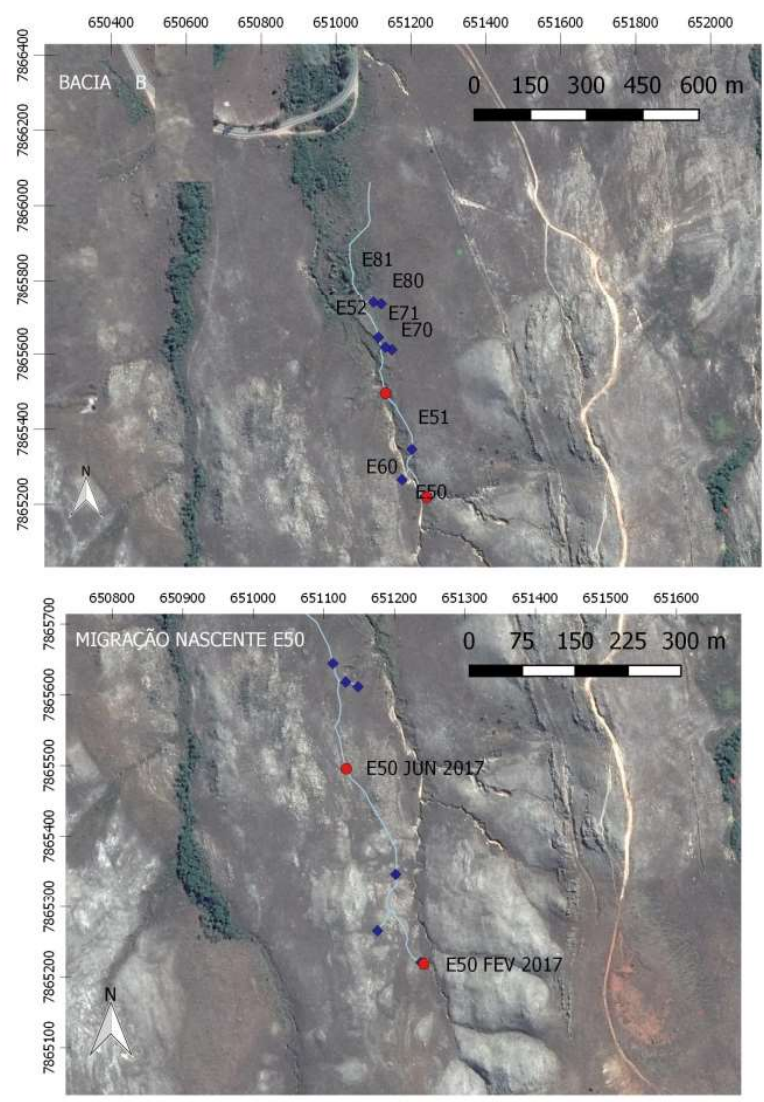
Os valores de TDS da E10 foram superiores aos do canal de $1^{\text {a }}$ ordem (E11) em março, junho e setembro de 2016 (em novembro de 2015 não havia exfiltração). Entretanto, o valor cai 13,3\% em fevereiro de 2017. Em março e em setembro, também há aumento de TDS entre o E11 e o E12, não ocorrendo a tendência de redução de valores com o aumento da vazão. Particularmente em março de 2016, houve uma importante redução do TDS entre a E10 e o E11 (-416 $\%$ ), e uma significativa elevação do valor entre o E11 e o E12 (+100\%). Percebe-se, portanto, os indícios do enriquecimento mineral superficial ao longo da rede de drenagem. Os fluxos escoam, localmente, por uma cobertura orgânica (serapilheira) de cerca de $20 \mathrm{~cm}$ de espessura. Esta cobertura deve ser responsável pelo enriquecimento geoquímico da água, principalmente entre os canais de $1^{\mathrm{a}}$ e $2^{\mathrm{a}}$ ordem.

Em ambas as bacias, os valores de TDS, significativamente superiores em setembro de 2016 e inferiores em junho de 2017, refletem a importante sazonalidade do clima regional. Esta constatação difere dos resultados encontrados por Felippe e Magalhães Jr (2016) em nascentes da mesma área, na Serra do Espinhaço, provavelmente devido ao período do ano hidrológico em que foram realizadas as amostragens. Os autores verificaram pequena variação dos dados entre os períodos seco e úmido, com valores sempre inferiores a $50 \mathrm{mg} / \mathrm{L}$. Este limiar foi ultrapassado em setembro na nascente E10 (76 mg/L), situada na bacia A, e em fevereiro de 2017 na nascente E30 e nos pontos E51 e E52, todos com indícios de influência de enriquecimento mineral superficial. No geral, os dados de TDS também foram superiores aos encontrados na Serra do Espinhaço por Leão et al. (2012), para canais de ordens superiores.

Trabalhos anteriores na Serra do Espinhaço encontraram valores de sílica que oscilam entre 2 e $10 \mathrm{mg} / \mathrm{L}$ (SALGADO; VALADÃO, 2003; FELIPPE, 2013; FELIPPE; MAGALHÃES JR, 2016). Geralmente, os baixos valores de sílica refletem a sua baixa solubilidade natural. Esta tendência se manteve nos resultados deste trabalho, mas com diversos pontos apresentando valores abaixo de $2 \mathrm{mg} / \mathrm{L} \mathrm{em}$ novembro de 2015 e março e junho de 2016. Por outro lado, os pontos com fluxos ativos em setembro de 2016 e junho de 2017 apresentaram valores bastante superiores. Em fevereiro de 2017 os valores caem bastante na maioria dos pontos. Deste modo, houve tendência de forte oscilação dos valores em função da sazonalidade, assim como verificado para o TDS. $\mathrm{Na}$ bacia A o significativo aumento entre junho e setembro atingiu $427 \%$ na nascente E10, $218 \%$ no E11, 185\% no E12, 424\% e 119\% nas nascentes E20 e E30, respectivamente, e 374\% no E31. Na bacia B, os percentuais de aumento foram bem maiores nos dois pontos com fluxos ativos: $5729 \%$ na nascente E50 e $8380 \%$ no ponto E51. Como a nascente E50 apresenta forte dinâmica migratória entre as estações úmida e seca esta variação pode ter, também, relação com o contato das águas subterrâneas com litologias distintas.

As coberturas orgânicas superficiais parecem contribuir com o enriquecimento de sílica ao longo da rede de drenagem. Há vários casos de aumento da concentração de sílica entre a água das nascentes e a dos canais de $1^{\text {a }}$ ordem, e entre a destes e a dos canais de $2^{\mathrm{a}}$ ordem. Os ácidos orgânicos acabam favorecendo a mobilização da sílica amorfa. Porém, dada à quase ausência de sílica amorfa nos quartzitos, as concentrações são normalmente baixas nas águas. A sílica é a principal componente do parâmetro TDS nas águas das nascentes situadas no Grupo Macaúbas da borda oeste da Serra do Cipó (Felippe e Magalhães, 2016). Nos quartzitos os carbonatos, metais alcalinos e a sílica amorfa são praticamente inexistentes, ocorrendo, entretanto, óxidos e a própria sílica na forma de quartzo. Por esse motivo o esvaziamento geoquímico dos quartzitos Macaúbas é bem mais lento do que em litologias adjacentes como as rochas carbonáticas do Grupo Bambuí. Para o caso do Galho do Miguel, devido ao elevado teor de pureza dos quartzitos, tal assertiva é ainda mais evidente.

Em relação aos dados de alcalinidade verifica-se uma tendência semelhante à da sílica ao longo da rede de drenagem. Os valores nas nascentes tendem a ser inferiores aos dos canais de $1^{\mathrm{a}} \mathrm{e} 2^{\mathrm{a}}$ ordens. As coberturas superficiais também explicariam este panorama ao condicionarem a mineralização das águas a partir da ação de ácidos orgânicos. Houve uma tendência de queda dos valores entre março e junho em todos os pontos com exfiltração ativa na bacia $\mathrm{A}$, passando a uma elevação generalizada em setembro. Já na bacia B não houve reduções de valores em junho e setembro, 
mas somente manutenção ou elevação. Em ambas as bacias os valores diminuíram em fevereiro de 2017. Entretanto, os dados variaram ligeiramente ao longo do tempo, situando-se, em grande parte, entre 3,0 e $5,0 \mathrm{mg} / \mathrm{L}$ de $\mathrm{CaCO}_{3}$. Exceção é feita a junho de 2017 nos pontos E10, E11, E12, E30 e E31, cujos valores de alcalinidade ficam entre 6 e $11 \mathrm{mg} / \mathrm{L}$ (Tabela 1), com significativo aumento em relação a fevereiro. Entretanto, no geral os valores são considerados muito baixos em comparação com os encontrados na literatura.

O parâmetro condutividade elétrica é complementar aos demais, auxiliando as interpretações à luz de suas relações com o TDS (Tabela 1). Os dados tenderam a ser inferiores em junho de 2016 e mais elevados em fevereiro de 2017, refletindo a sazonalidade pluviométrica. Os maiores valores ocorreram nos pontos E80 (Bacia B) - 14,01 $\mu \mathrm{S} / \mathrm{cm}-$ em junho de 2016, e E10 (bacia A) - 14,91 $\mu \mathrm{S} / \mathrm{cm}$ - em junho de 2017. Em fevereiro de 2017, alguns dados parecem confirmar o comportamento do TDS e a influência da lixiviação de coberturas intemperizadas pelos fluxos superficiais. $\mathrm{Na}$ sequência E10-E11-E12, os valores passam de $8,0 \mu \mathrm{S} / \mathrm{cm}$ na nascente, para $15,39 \mu \mathrm{S} / \mathrm{cm}$ no E11 e $7,58 \mu \mathrm{S} / \mathrm{cm}$ no E12 (enriquecimento geoquímico entre a nascente e o canal de $1^{\mathrm{a}}$ ordem). Os valores também aumentam nos pontos E21 e E51 (canais de $1^{\mathrm{a}}$ ordem) em relação às nascentes. Por outro lado, em fevereiro de 2017 houve redução dos valores dos canais de $1^{\text {a }}$ ordem E21 e E51 em relação às nascentes E20 e E50, respectivamente. Em junho de 2017 a sequência E10E11-E12 não apresentou a mesma tendência de fevereiro de 2017. O aumento progressivo deu lugar à redução da condutividade ao longo da rede de drenagem: $14,91 \mu \mathrm{S} /$

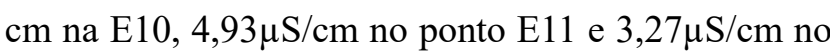
E12. Em fevereiro de 2017 o acumulado pluviométrico deve ter sido eficiente ao ponto de gerar zonas de encharcamento superficial da serapilheira favoráveis à concentração de ácidos orgânicos.

Deste modo, parece ocorrer um enriquecimento mineral superficial progressivo ao longo da drenagem nos períodos úmidos (fevereiro), quando nascentes difusas, áreas úmidas e zonas de encharcamento de serapilheira (no caso da bacia A) se formam e/ou se expandem ao longo da drenagem. Já nos períodos secos (junho), há um decréscimo progressivo, pois o enriquecimento geoquímico advém primordialmente do meio subterrâneo, fato expresso nos maiores valores das nascentes. As figuras 9 e 10 ilustram pontos da rede de drenagem que sofrem predomínio de enriquecimento geoquímico superficial e subterrâneo nas duas bacias.

Quase todos os parâmetros geoquímicos analisados via ICP apresentaram concentrações abaixo do limite de detecção nos períodos analisados (Tabela 4). As única exceção foi o $\mathrm{Mg}$, mas o número elevado de pontos com concentrações acima do limite de detecção apresentou, ainda assim, valores abaixo de $0,1 \mathrm{mg} / 1$, em sua grande maioria. Os elementos $\mathrm{Al}$ e Ca também foram detectados em uma série de pontos, no entanto, em campanhas pontuais. O ponto E11, na Bacia A, apresentou, em novembro de 2015, o maior valor de $\mathrm{Mg}$ e Ca de todo o conjunto analisado $(0,18$ e $0,34 \mathrm{mg} / 1$, respectivamente $)$.

Tabela 4: Concentrações de elementos geoquímicos obtidos via ICP

\begin{tabular}{|c|c|c|c|c|c|c|c|c|c|c|c|c|c|c|c|c|c|c|c|}
\hline \multirow[b]{2}{*}{ HIERARQUIA } & \multirow[b]{2}{*}{ AMOSTRA } & \multicolumn{6}{|c|}{$\mathrm{Mg}$} & \multicolumn{6}{|c|}{ Al } & \multicolumn{6}{|c|}{$\mathrm{Ca}$} \\
\hline & & nov/15 & $\mathrm{mar} / 16$ & \begin{tabular}{l|l} 
jun/16 \\
\end{tabular} & set/16 & fev/17 & jun/17 & nov/15 & $\mathrm{mar} / 16$ & jun/16 & set/16 & $\mathrm{fev} / 17$ & jun/17 & nov/15 & $\mathrm{mar} / 16$ & jun/16 & set/16 & $\mathrm{fev} / 17$ & jun/17 \\
\hline 0 & E10 & 0,0407 & $\begin{array}{r}0,0120 \\
\end{array}$ & 0,0059 & 0,0890 & & 0,0435 & & LD & LD & LD & LD & LD & & LD & LD & LD & LD & LD \\
\hline 1 & E11 & 0,1845 & 0,0248 & 0,0027 & 0,0790 & LD & $0,0659 \mathrm{~L}$ & LD & LD & LD & LD & LD & LD & $0,3401 \mid \mathrm{L}$ & LD & LD & LD & LD & LD \\
\hline 2 & E12 & 0,0977 & 0,0156 & & 0,0986 & LD & $0,0418 \mid L$ & LD & LD & & LD & LD & LD & $0,0245 \mid$ & LD & & LD & LD & LD \\
\hline 0 & E2O & 0,0773 & & 0,0101 & 0,0713 & \begin{tabular}{|l|}
0,0265 \\
\end{tabular} & & LD & & LD & LD & LD & & 0,1515 & & LD & LD & LD & \\
\hline 1 & E21 & 0,1788 & & 0,0021 & & \begin{tabular}{|l|l|} 
LD \\
\end{tabular} & & LD & & LD & & LD & & 0,2614 & & LD & & LD & \\
\hline 0 & E30 & 0,0698 & & 0,0194 & 0,0503 & \begin{tabular}{|l|}
0,0311 \\
\end{tabular} & $0,0660 \mid L$ & LD & & LD & LD & LD & & 0,0834 & & LD & LD & LD & \\
\hline 1 & E31 & 0,0294 & & 0,0179 & 0,0673 & 0,0544 & $0,0733 L$ & LD & & LD & LD & LD & LD & 0,0971 & & LD & LD & $L D$ & 0,1398 \\
\hline 0 & E50 & & 0,0218 & LD $\quad \mathrm{L}$ & LD & \begin{tabular}{|l|l|} 
LD \\
\end{tabular} & 0,0351 & & LD & LD & LD & LD & LD & \begin{tabular}{l|l}
$\mathbf{L D}$ & $\mathrm{L}$
\end{tabular} & LD & LD & LD & LD & LD \\
\hline 1 & E51 & & 0,0213 L & LD & \begin{tabular}{|l|}
0,1002 \\
\end{tabular} & \begin{tabular}{|l|}
0,0305 \\
\end{tabular} & 0,0393 & & LD & LD & LD & LD & LD & LD & LD & LD & LD & LD & LD \\
\hline 2 & E52 & & 0,0030 & & & \begin{tabular}{|l|l|} 
LD \\
\end{tabular} & 0,0714 & & LD & & & LD & LD & LD & LD & & & LD & LD \\
\hline 0 & E60 & & 0,0301 & & & LD & & & LD & & & LD & & & LD & & & LD & \\
\hline 0 & E70 & & 0,0249 & & & LD & & & \begin{tabular}{|r|}
0,0878 \\
\end{tabular} & & & LD & & & 0,0080 & & & LD & \\
\hline 1 & E71 & & 0,0122 & & & LD & & & 0,0851 & & & LD & & & \begin{tabular}{|l|l|} 
LD \\
\end{tabular} & & & LD & \\
\hline 0 & E80 & & 0,0479 & & & \begin{tabular}{|l|}
0,0733 \\
\end{tabular} & 0,0522 & & LD & & & LD & LD & & LD & & & \begin{tabular}{|r|}
0,1473 \\
\end{tabular} & 0,1961 \\
\hline 1 & E81 & & 0,0120 & & & & & & 0,0343 & & & & & & LD & & & & \\
\hline
\end{tabular}

Obs: O ICP é capaz de detectar $\mathrm{Mg}, \mathrm{Al}, \mathrm{Ca}, \mathrm{Cr}, \mathrm{Fe}, \mathrm{Co}, \mathrm{Cu}, \mathrm{Cd}, \mathrm{Ti}, \mathrm{Mn}, \mathrm{Ni}, \mathrm{Zn}, \mathrm{Ba}, \mathrm{Pb}$, no entanto, os elementos não representados não alcançaram o limite de detecção (LD) para as amostras analisadas no contexto da Serra do Espinhaço. 


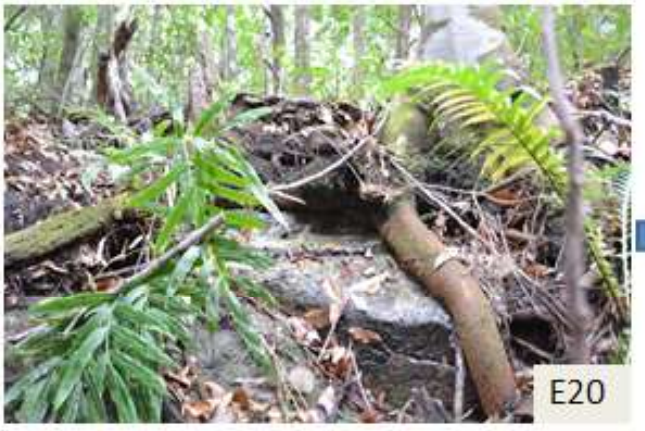

Nascente pontual biogênica: Enriquecimento geoquímico subterrâneo em ambas as estações (úmidae chuyosa)

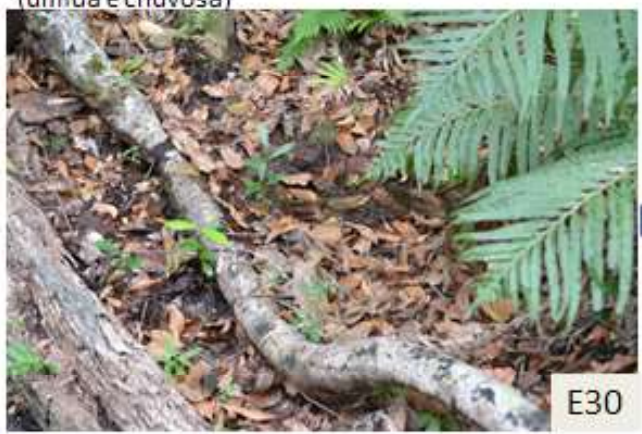

Nascente difusa: Enriquecimento geoquímico subterrâneo e superficial em ambas as estações

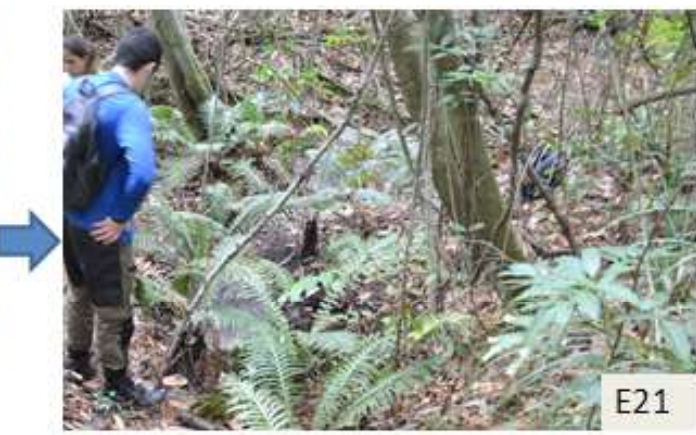

Canal de primeira ordem: Enriquecimento geoquímico superficial na estação úmida

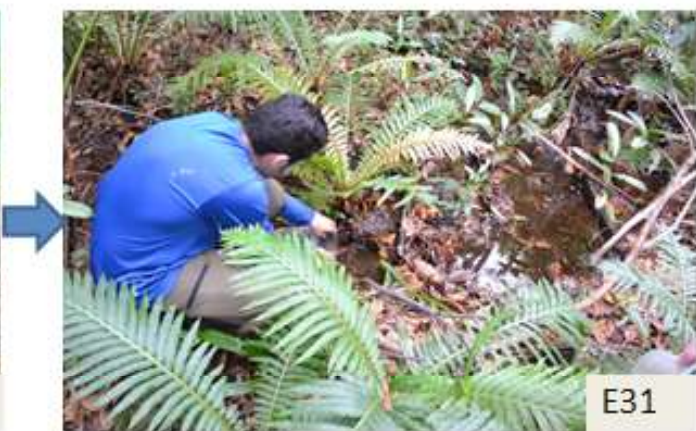

Canal de primeira ordem: Enriquecimento geoquímico superficialem ambas as estações

Figura 9 - Imagens ilustrativas de pontos da bacia A com enriquecimento geoquímico predominante nas coberturas superficiais ou no meio subterrâneo

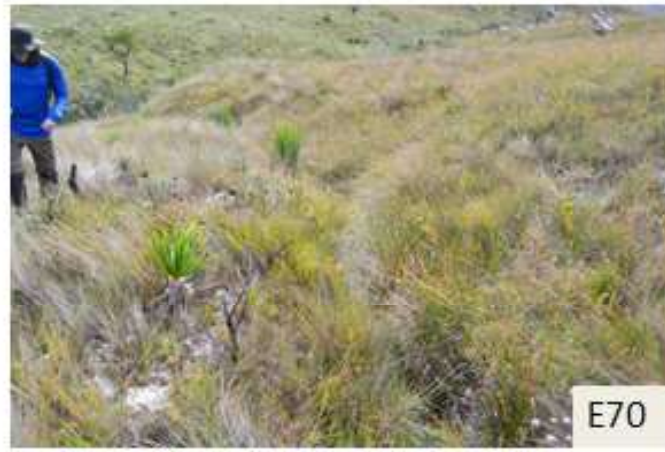

Nascente difusa: Enriquecimento geoquímico subterrâneo e superficial na estaçãoúmida

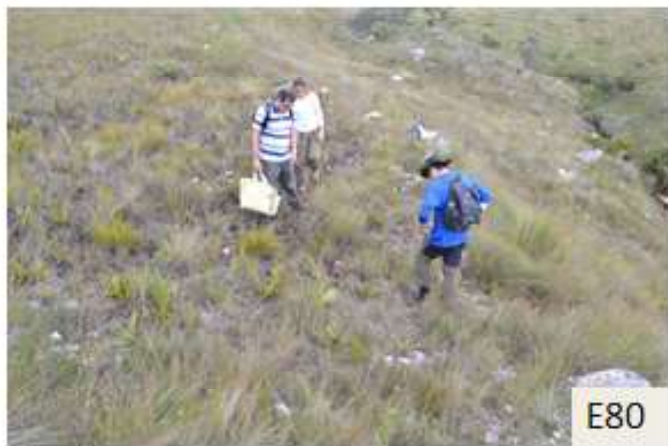

Área Úmida e nascente difusa: Enriquecimento geoquímico subterrâneo e superficial na estação úmida

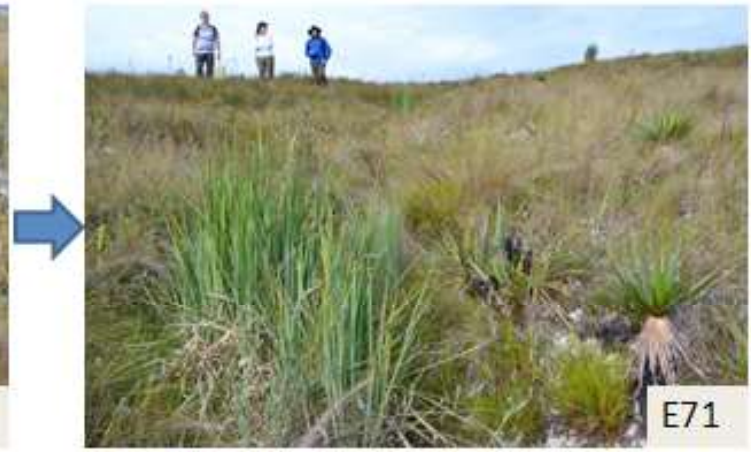

Canal de primeira ordem: Enriquecimento geoquímico superficial na estação úmida

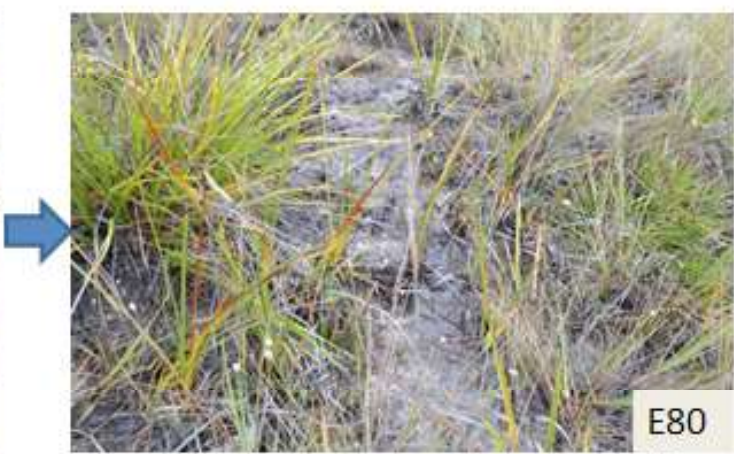

Detalhe do substrato encharcado da nascente difusa e sítio de enriquecimento geoquímico superficial na estação úmida

Figura 10 - Imagens ilustrativas de pontos da bacia B com enriquecimento geoquímico predominante nas coberturas superficiais ou no meio subterrâneo 


\section{Conclusões}

Em ambientes tropicais a análise geoquímica das águas apresenta-se como uma alternativa importante para o estudo da evolução do modelado. Durante o período de monitoramento houve uma tendência importante de influência da sazonalidade, com mudanças significativas entre setembro e junho.

A hierarquia fluvial parece ser um componente importante na compreensão da carga química das águas fluviais. Para o caso das cabeceiras estudadas na Serra do Cipó, há uma tendência de aumento do TDS com a diminuição da hierarquia. Por outro lado, os dois parâmetros químicos que constituem o TDS (considerados pela literatura como estando entre os mais significativos na mineralogia das águas desse contexto geológico) analisados nesse estudo, evidenciam o contrário. Isso leva a crer que a presença de ácidos orgânicos relacionados à decomposição da matéria orgânica em ambientes de hidromorfismo pode ser mais relevante do que se pensava anteriormente; o que explicaria nascentes com TDS mais elevado e sílica e alcalinidade mais baixas do que seus canais de maior hierarquia.

A análise dos valores de TDS e de parâmetros complementares demonstra que parece haver, em termos gerais, uma cadeia de relações diretas entre o regime pluviométrico, a formação de níveis freáticos suspensos, a saturação das coberturas superficiais, e o enriquecimento geoquímico da água devido à ação dos ácidos orgânicos destas coberturas. Como ilustrado nas figuras 9 e 10, este enriquecimento ocorre a partir de dois processos principais:

- ativação ou expansão de nascentes difusas, com formação de áreas úmidas em zonas de campos rupestres (bacia B) ou de mata estacional semidecidual (bacia A). A saturação do solo e o alagamento superficial favorecem a liberação de ácidos orgânicos, a dissolução química e o surgimento de sinais de hidromorfismo nas coberturas orgânicas;

- encharcamento de serrapilheira na Bacia A por acumulação de águas pluviais, favorecendo a formação de brejos onde há a liberação de ácidos orgânicos e outros elementos para os canais de $1^{\mathrm{a}}$ e $2^{\mathrm{a}}$ ordens.

Em ambos os casos, o enriquecimento geoquímico superficial tende a ocorrer na estação úmida, quando ocorre a elevação dos níveis freáticos, a saturação dos solos e a expansão de áreas úmidas e encharcadas. Nos períodos secos o enriquecimento geoquímico advém prioritariamente dos aquíferos subsuperficiais. Estes processos dependem, também, dos importantes reflexos da sazonalidade pluviométrica na migração de pontos de exfiltração. Nascentes podem migrar centenas de metros de montante para jusante, e esta dinâmica pode ser acompanhada da mudança do tipo de nascentes entre as estações úmida e seca. É o caso da E50 que passa de difusa, em fevereiro de 2017, para pontual em junho do mesmo ano. Esta mudança no tipo de exfiltração em função da sazonalidade pluviométrica influencia diretamente no vetor preferencial de enriquecimento geoquímico das águas, já que a formação de pontos de exfiltração difusa determina o predomínio do enriquecimento superficial, enquanto os pontos de exfiltração pontual tendem a representar o predomínio do enriquecimento geoquímico subterrâneo.

$\mathrm{O}$ enriquecimento geoquímico superficial das águas em nascentes difusas parece ser refletido em vários segmentos de ambas as bacias. Na nascente E10, de tipo pontual, o encharcamento de serrapilheira parece ser o fenômeno responsável pelo enriquecimento geoquímico na sequência E10-E11-E12 em fevereiro de 2017. A cobertura vegetal também é um fator relevante na diferenciação da dinâmica hidrológica e do enriquecimento geoquímico. Nas áreas de matas, incluindo as ciliares, as vazões tendem a ser maiores do que nas áreas de campos rupestres nas estações úmida e seca em ambas as bacias. Por consequência, a maior diluição tende a resultar em menores valores de TDS.

Apesar de diferenças encontradas entre as bacias, ambas representam a realidade geoquímica das águas da Serra do Cipó (e do Espinhaço de um modo geral). Os valores muito baixos dos elementos analisados corroboram a resistência dos materiais aos processos de intemperismo químico. Nuances podem estar relacionadas a características pedológicas, geológicas, vegetacionais e morfológicas muito específicas e locais que somente estudos verticalizados permitiriam compreender. Em função dos resultados, percebe-se que a utilização do ICP como técnica de pesquisa das perdas geoquímicas na Serra do Cipó mostrou-se pouco eficiente. As características geológicas locais (elevada resistência ao intemperismo) resultam em concentrações muito baixas para quase todos os elementos, sem mesmo atingir o limite de detecção das técnicas em muitos casos. 


\section{Agradecimentos}

Ao CNPq pelo apoio financeiro relativo ao projeto "O papel das nascentes e cabeceiras de drenagem na evolução de unidades do relevo de Minas Gerais por meio da análise dos processos de desnudação geoquímica". Ao Laboratório de Geomorfologia do IGC/UFMG e ao Grupo de Pesquisa Geomorfologia e Recursos Hídricos (CNPq).

\section{Referências Bibliográficas}

ALMEIDA-ABREU, P. A. O supergrupo Espinhaço da Serra do Espinhaço meridional (Minas Gerais): o rifte, a bacia e o orógeno. Belo Horizonte: Geonomos, v. 3, n. 1, p. 1-18, 1995. DOI:10.18285/geonomos.v3i1.211. Acesso em: 14/01/2018

ALMEIDA-ABREU, P. A.; RENGER, F. E. Serra do Espinhaço meridional: um orógeno de colisão do mesoproterozóico. Revista Brasileira de Geociências, v. 32, n.1, p. 1-14, 2002. > http:// ppegeo.igc.usp.br/index.php/rbg/article/view/10389< Acesso em: $14 / 01 / 2018$.

APHA - AMERICAN PUBLIC HEALTH ASSOCIATION; AWWA-AMERICAN WATER WORKS ASSOCIATION; WEF - WATER ENVIRONMENT FEDERATION. (2012) Standard Methods for Examination of Water and Wastewater. Washington: APHA, 22 har., Cdr Edition, 2012, 1496p.

CHEMALE JR, F.; DUSSIN, I. A.; MARTINS, M.; SANTOS, M. N. Nova abordagem tectono-estratigráfica do Supergrupo Espinhaço em sua porção meridional (MG). Belo Horizonte: Geonomos, v. 19, CPMTC-UFMG, p. 173-179, 2011. DOI: 10.18285/geonomos.v19i2.52. Acesso em: 14/01/2018.

FEITOSA, A. C.; MANOEL-FILHO, J. (eds.). Hidrogeologia: conceitos e aplicações. $2^{\mathrm{a}}$ ed. Fortaleza: CPRM, 1997. $412 \mathrm{p}$.

FELIPPE, M. F. Gênese e dinâmica de nascentes: contribuições a partir da dinâmica hidrogeomorfológica em região tropical. Tese (Doutorado em Geografia e Análise Ambiental). Instituto de Geociências, Universidade Federal de Minas Gerais, Belo Horizonte. 2013. 185 p.

FELIPPE, M. MAGALHÃES Jr, A P. A contribuição das nascentes na desnudação geoquímica: Borda oeste da Serra do Espinhaço Meridional (Minas Gerais, Brasil). Brasília: Revista Brasileira de Geomorfologia, v17, n.1, p. 79-92, 2016. DOI: 10.20502/rbg.v17i1.878. Acesso em: 14/01/2018

HINDI, E.; ROSA-FILHO, E.; BITTENCOURT, A.; XAVIER, J., Características hidrogeológicas do aqüífero costeiro da Ilha dos Valadares, PR (Brasil) e sua utilização para abastecimento público. Revista Latino-Americana de Hidrogeologia, n.3, p. 19-31, 2003. > http://revistas.ufpr.br/hidrogeologia/article/ viewFile/2633/2174< Acesso em: 14/01/2018

IBGE - INSTITUTO BRASILEIRO DE GEOGRAFIA E ESTATÍSTICA (2002) Rio de Janeiro: Mapa de climas do Brasil. Escala 1:5.000.000. IBGE

IBGE - INSTITUTO BRASILEIRO DE GEOGRAFIA E ESTATÍSTICA (2006) Rio de Janeiro: Mapa de unidades de relevo do Brasil. Escala 1:5.000.000. IBGE

IEF - INSTITUTO ESTADUAL DE FLORESTAS (2009) Belo Horizonte: Mapa das coberturas vegetais do estado de Minas Gerais. Escala 1:1.000.000. IEF

LEÃO, M. R.; REZENDE, E. A.; SALGADO, A. A.; NAILINI JR, H. A. Erosão, denudação e evolução do relevo da média Serra do Espinhaço meridional, Minas Gerais. Brasília: Revista Brasileira de Geomorfologia, v.13, n.2, p.113-124, 2012. DOI: 10.20502/rbg.v13i2.369. Acesso em: 14/01/2018

MAGAlHÃes JR., A. P.; FELIPPE, M. F. (2012) The Importance Of River Springs In Sustainable Water Management: The City Of Belo Horizonte, Brazil. In: BILIBIO, C.; HENSEL, O.; SELBACH, J.F. (org.) Sustainable water management in the tropics and subtropics - and case studies in Brazil. Unipampa; UNIKASSEL; PGCult-UFMA, Jaguarão: v.3, p. 299-346.

SAADI, A. A geomorfologia da Serra do Espinhaço em Minas Gerais e de suas margens. Belo Horizonte: Geonomos, v. 3, n. 1, p. 41-63, 1995. DOI: 10.18285/geonomos.v3i1.215. Acesso em: $14 / 01 / 2018$

SAlGADO, A. A.; VALADÃO, R. C. Contribuição da Desnudação Geoquímica na Evolução da Erosão Diferencial no Espinhaço Meridional - MG. Brasília: Revista Brasileira de Geomorfologia. Brasília: v. 4, No 2, p. 31-40, 2003. DOI:10.20502/rbg.v4i2.22. Acesso em: 14/01/2018

SALGADO, A. A. R.; VARAJÃO, C. A. C.; COLIN, F.; BRAUCHER, R.; NALINI

JUNIOR, H. A.; VARAJÃO, A. F. D. O papel da denudação geoquímica no processo de erosão diferencial no Quadrilátero Ferrífero/MG. Brasília: Revista Brasileira de Geomorfologia, v. 5,n. 1, p. 55-69, 2004. DOI: 10.20502/rbg.v5i1.32. Acesso em: $14 / 01 / 2018$

SARDINHA, D. S.; BONOTTO, D. N.; GODOY, L. H.; CONCEIÇÃO, F. T.; MORENO, M.M. T., Denudação química e implicações na composição das águas superficiais da bacia do 
Relações entre Perdas Geoquímicas e Configuração Geomorfológica de Bacias Fluviais de Baixa Ordem

rio Jaú (SP). Brasília: Revista Brasileira de Geomorfologia, v.13, n.3, p.337-349, 2012. DOI: 10.20502/rbg.v13i3.284. Acesso em: 14/01/2018

TUCCI, C. E. M. Hidrologia: Ciência e Aplicação. $2^{\mathrm{a}}$ ed. Porto Alegre: ABRH, 2000. 943p.
UHLEIN, A.; TROMPETTE, R.; EGYDIO-SILVA, M. Rifteamentos superpostos e tectônica de inversão na borda sudeste do cráton do São Francisco. Belo Horizonte: Geonomos, v. 3, n. 1, p.99-107, 1995. DOI: 10.18285/geonomos.v3i1.219. Acesso em: 14/01/2018 